\title{
Blood pressure and quality of life in youth enrolled in a culinary skills, family mealtime and physical activity program: Pilot study icook 4-h
}

\author{
Erin Smith \\ West Virginia University
}

Follow this and additional works at: https://researchrepository.wvu.edu/etd

\section{Recommended Citation}

Smith, Erin, "Blood pressure and quality of life in youth enrolled in a culinary skills, family mealtime and physical activity program: Pilot study icook 4-h" (2014). Graduate Theses, Dissertations, and Problem Reports. 128.

https://researchrepository.wvu.edu/etd/128

This Thesis is protected by copyright and/or related rights. It has been brought to you by the The Research Repository @ WVU with permission from the rights-holder(s). You are free to use this Thesis in any way that is permitted by the copyright and related rights legislation that applies to your use. For other uses you must obtain permission from the rights-holder(s) directly, unless additional rights are indicated by a Creative Commons license in the record and/ or on the work itself. This Thesis has been accepted for inclusion in WVU Graduate Theses, Dissertations, and Problem Reports collection by an authorized administrator of The Research Repository @ WVU. For more information, please contact researchrepository@mail.wvu.edu. 


\title{
BLOOD PRESSURE AND QUALITY OF LIFE IN YOUTH ENROLLED IN A CULINARY SKILLS, FAMILY MEALTIME AND PHYSICAL ACTIVITY PROGRAM: PILOT STUDY ICOOK 4-H
}

\author{
Erin Smith, BS \\ Thesis submitted to the \\ Davis College of Agriculture, Natural Resources and Design at \\ West Virginia University \\ in partial fulfillment of the requirements \\ for the degree of \\ Master of Science \\ in \\ Nutrition and Food Science
}

\author{
Melissa D. Olfert, DrPH, MS, RD, LD, Chair \\ Amy E. Root, PhD \\ Sue Flanagan, MS \\ Department of Animal and Nutritional Sciences
}

Morgantown, West Virginia

2014

Keywords: Blood Pressure, Quality of Life, Youth, BMI, Childhood Obesity

Copyright 2014 Erin Smith 


\section{ABSTRACT \\ Blood Pressure and Quality of Life in Youth Enrolled in a Culinary Skills, Family Mealtime and Physical Activity Program: iCook 4-H Pilot Study}

\section{Objective:}

The pilot study objective is to determine if blood pressure (BP) and perception of quality of life (QoL) in 9-10 y/o youth changes after a 12 week 6-session program focusing on culinary skills, family mealtime and physical activity.

\section{Methods:}

Pre-post treatment only assessments were collected at 0 and 4 months for child/adult dyads (n=49 dyads). Five states (ME, NE, SD, TN, WV) recruited and delivered 6 sessions every two weeks that focused on increasing cooking skills, family mealtime, and physical activity. During $\mathrm{BP}$ assessments, each child had an initial rest of 5 min with 2 min rest between measurements using a digital Omron BP machine with averages recorded. The Peds-QL tool assessed perceived QoL in youth related to their functioning physically, emotionally, and socially.

\section{Results:}

At baseline, 93\% $(n=45)$ of participants had normal BP and 6\% $(n=3)$ were pre-hypertensive. At 4-month post assessment $(n=43)$, 91\% $(n=39)$ had normal BP and 7\% $(n=4)$ were prehypertensive. Significant differences were seen in QoL between pre and post-measurements (mean difference $=-0.284 ; \mathrm{p}<0.01)$, indicating the perception of QoL increased. No correlations were seen between QoL and BP at pre- or post-test.

\section{Conclusions and Implications:}

While BP varied little from pre to post, QoL increased over the 4 month pilot study. However, based on findings, there was no correlation between BP and QoL, and the increase in QoL was not 
reflected in BP. Increased QoL could have a positive effect on systemic responses such as BP, but since most youth had normal BP, little effect would be expected. 


\section{ACKNOWLEDGMENTS}

First and foremost, I would like to thank God. Without him, everything I have done would not be possible.

I would also like to thank Dr. Melissa Olfert, for providing me with the opportunity to work as a campus coordinator in a multi-state group project, titled iCook 4-H. I would also like to thank her for her time and expertise throughout the past two years.

Next, I would like to thank my additional committee members Dr. Amy Kennedy and Sue Flanagan for their continued support and flexibility. I would also like to extend my appreciation to Dr. Christa Lilly and Kelsey Ash for their statistical advice and expertise.

I would like to thank the participants in Olfert Research Lab (ORL) for their help throughout my entire two years here. Your support and encouragement helped me through the past two years.

I would also like to thank the participants in the iCook4-H study, because without them none of this would have been possible.

Lastly, I would like to thank my family and close friends for their continued support and encouragement throughout the completion of my Master's Program. 


\section{TABLE OF CONTENTS}

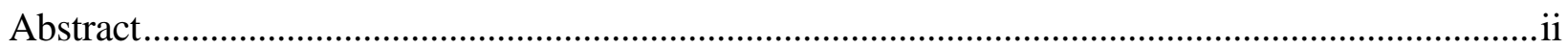

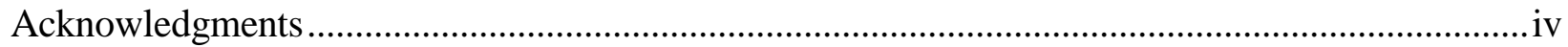

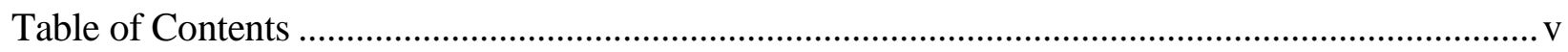

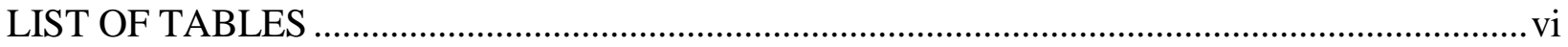

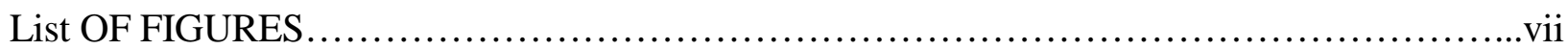

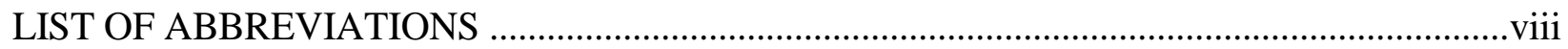

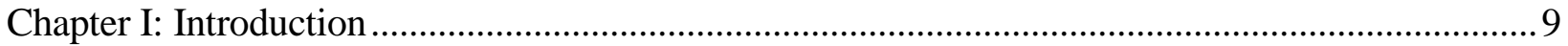

Chapter II: Blood Pressure and its Effects on Quality of Life in Children and Adolescents.............12

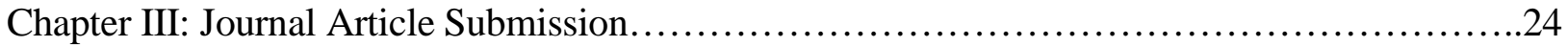

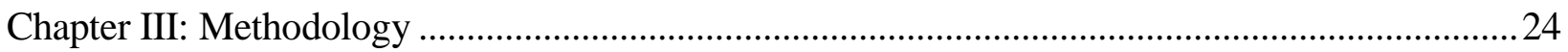

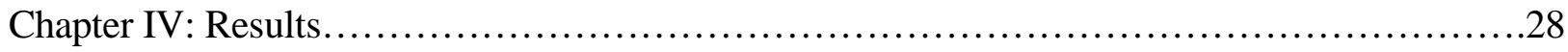

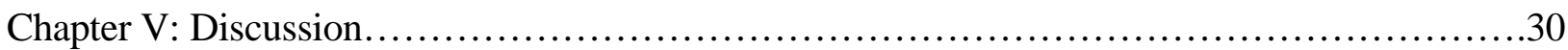

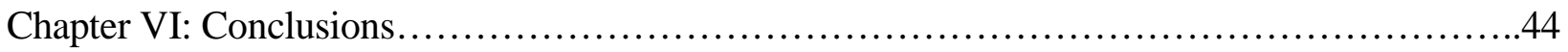

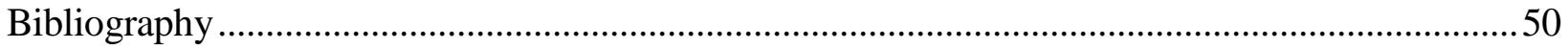

Appendix A: IRB Approval and Consent/Assent and Information Form.........................39

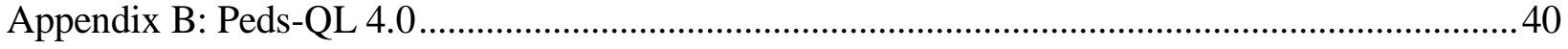

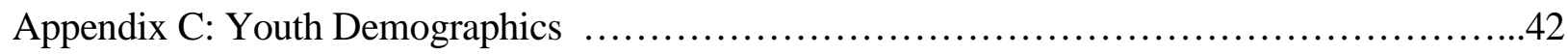

Appendix D : Anthropometric, Blood Pressure, and Body Composition Measures ................43

Appendix E: A Pocket Guide to Blood Pressure Measurement in Children........................52 


\section{LIST OF TABLES}

Table 1.0 Comparison of BP and its Effect on HRQoL..................................19

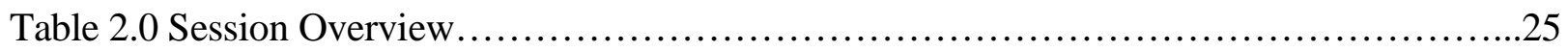

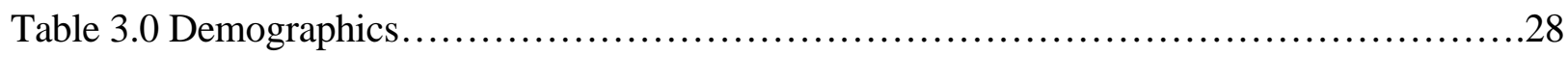

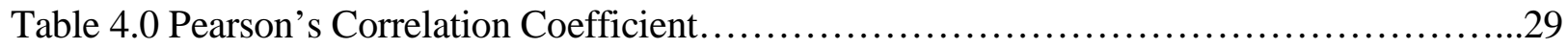

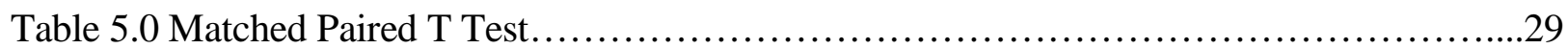




\section{List of Figures}

Figure 1.0 Goals of iCook4-H.................................................. 10

Figure 2.0 Social Ecological Model...............................................11

Figure 3.0 Social Cognitive Model............................................... 12 


\section{LIST OF ABBREVIATIONS}

Blood Pressure -BP

Systolic Blood Pressure- SBP

Diastolic Blood Pressure- DBP

High density lipoprotein- HDL

Low density lipoprotein- LDL

Body Mass Index- BMI

Health Related Quality of Life- HRQoL

Quality of Life- QoL

Pediatric Quality of Life- Peds-QL

Quality of Urban Life- QUL

Community-based participatory research- CBPR

Social Ecological Theory- SET

Social Cognitive Theory- SCT

Inter Rater Reliability- IRR

Family Base Behavioral Therapy- FBBT

Center for Disease Control- CDC

Cardiovascular Disease- CVD

Waist circumference- WC

Mental Component Summary- MCS

Physical Component Summary- PCS 


\section{CHAPTER I}

\section{INTRODUCTION}

With increasing rates of obesity especially in young citizens of the United States (US), it is important that Americans focus on promoting healthier lifestyles. In the US, heart disease is the leading cause of death. ${ }^{1}$ The US Government has increased funding to programs to help with the obesity initiative in adolescence like the Let's Move campaign that was launched by first lady Michelle Obama on February 9, 2010. Obesity has become an increasingly large problem in youth and is leading to more co-morbidities that increase risk for developing heart disease in adulthood. ${ }^{2}$ The number of children ages 6-11 years identified as obese in the United States increased from 7\% in 1980 to nearly $18 \%$ in 2012 .. Similarly, the percentage of adolescents aged $12-19$ years who

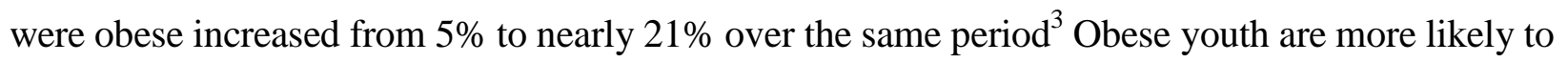
have risk factors for cardiovascular disease, such as high cholesterol or high blood pressure. In a population-based sample of 5 to 17 -year-olds, $70 \%$ of obese youth had at least one risk factor for cardiovascular disease. ${ }^{2}$ Social and psychological problems are often seen in obese youth as well. ${ }^{3}$

With iCook4-H, physical activity is one of the main focuses in the curriculum. The American Heart Association recommends 2 hours of screen time per day for adolescents. ${ }^{42}$ The average amount that 8-18-year old adolescents spend is 7.5 hours a day using entertainment media, including, TV, computers, video games, cell phones and movies. ${ }^{43}$ Due to the increase in screen time, we inversely see a decrease in physical activity which is related to an increase in obesity in our youth. Gordon-Larson et al. stated that adolescents are not getting the recommended moderate to vigorous activity 5 times per week and this is carrying over into adulthood which coincides with the increased obesity rates. ${ }^{41}$ Excess weight at young ages has been linked to higher and earlier death rates in adulthood. ${ }^{42}$ 
Family meal time is another focus in the curriculum developed for iCook4-H. Families sitting down at the dinner table and enjoying each other's company has decreased significantly compared to past generations. Eto K. et al. looked at a total of 236 participants and family meal frequency showed that $73 \%$ reported a positive intention to eat meals as a family. They also found that $84 \%$ enjoyed eating meals with their family, $71 \%$ thought eating family meals was important, and $68 \%$ looked forward to family meals. The actual family meal frequency showed that $73 \%$ of adolescents reported to only eating breakfast with their family 2 days or fewer per week and $17 \%$ reported having family breakfast 5 days or more. Enjoyment of family meals in youth remains high, but as they get older the perception of barriers to eating meals together increases. This leads to the proposition that encouraging family meal time and showing the benefits it can have could have a positive impact on health. It also would be beneficial to trouble shoot and work through ways to overcome barriers to eating meals together. ${ }^{44}$ Since family meals are positively associated with making more healthful decisions, this is a valuable component in developing educational curriculum focusing on making nutritious decisions.

Culinary skills are the third and last main component in the iCook4-H curriculum. Research suggests the decline in cooking ability is related to the lack of healthy home cooked meals ${ }^{45}$ The food budget spent on away-from-home meals has also been gradually increasing since the mid 1970's. Today Americans spend 49\% of their budget on food with $32 \%$ of their calories on awayfrom-home foods. ${ }^{46}$ This demonstrates the need to focus on adolescents and their parents cooking skills, in hope of increasing knowledge and ability to create healthier meals at home.

\section{Figure 1.0 Goals of iCook4-H}

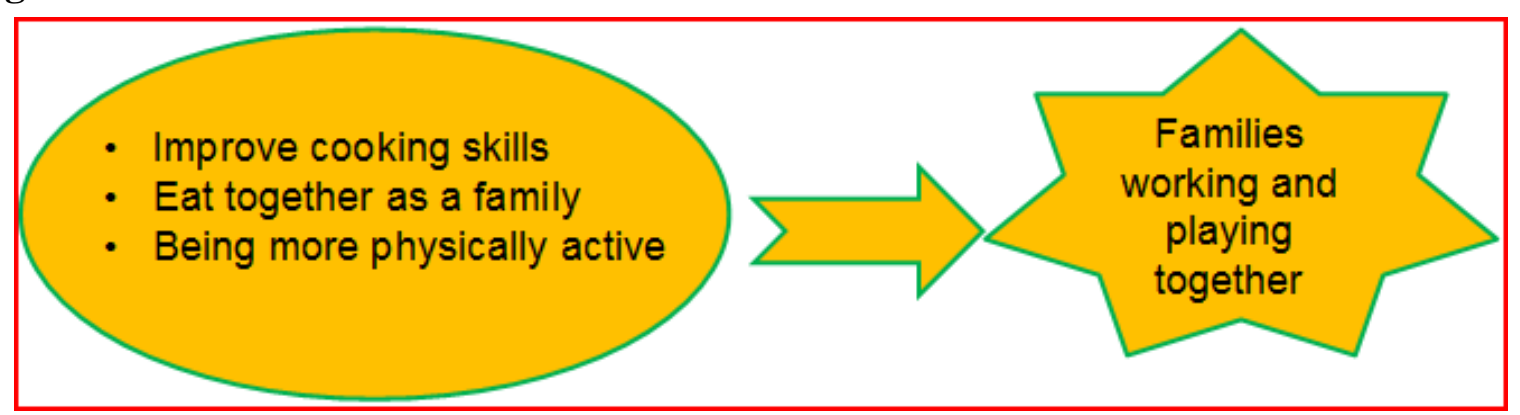




\section{Community-based Participatory Research}

Community-based participatory research (CBPR) is an approach to research meant to enrich the value of a study for both researchers and the community being studied. ${ }^{16}$ "According to the Kellogg Foundation's Community Scholars Program, CBPR is a collaborative approach to research that equitably involves all partners in the research process and recognizes the unique strengths that each brings.. ${ }^{17}{ }^{18}$ CBPR begins with a research topic of importance to the community with the objective of combining knowledge and action to improve the community. ${ }^{17}$ In CBPR, community members are equal partners with academic researchers in defining the problem, collecting information, interpreting data, and developing solutions that are applicable to the situations. Community members are recognized as experts in their own right and their knowledge is equally valued as is academic expertise. ${ }^{19}$ The CBPR team forms a relationship where they are continually learning from each other and seeing issues and solutions from different perspectives. Social ecological theory (SET) is often important with curriculum development as well as determining which measurement tools to be used. SET looks at the interactions within social factors, organizational and community factors, interpersonal influences as well as individual factors and the contexts of people-environment relations that make up well-being. ${ }^{47}$ Below is a picture depicting the social ecological model.

\section{Figure 2.0 Social Ecological Model}

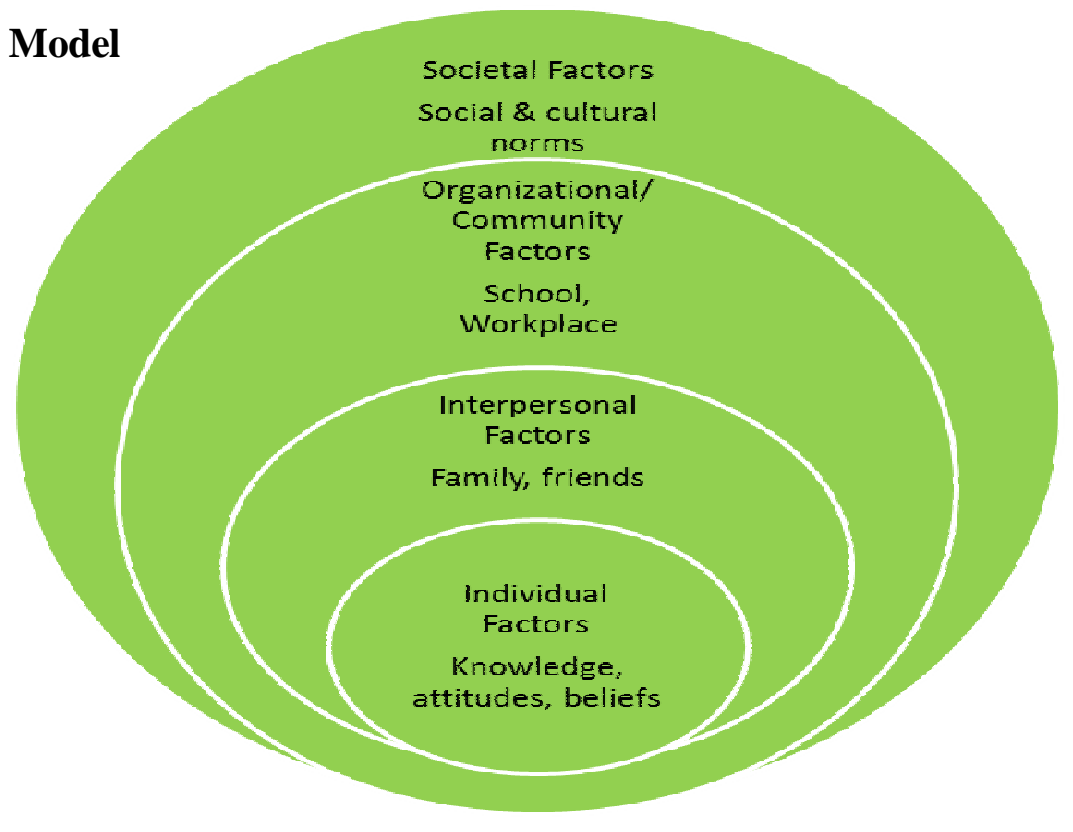


CBPR allows different perspectives to help determine what could be potentially increasing obesity as well as many other health disparities. Drawing from SET the Social Cognitive Theory (SCT) is also critical to iCook4-H development. The SCT looks at self-efficacy, reinforcement, self-control, observational learning, and reciprocal determinism. SCT considers many levels of the social ecological model in addressing behavior change of individuals. ${ }^{48}$ These theories prove to be important in curriculum development.

\section{Figure 3.0 Social Cognitive Model}

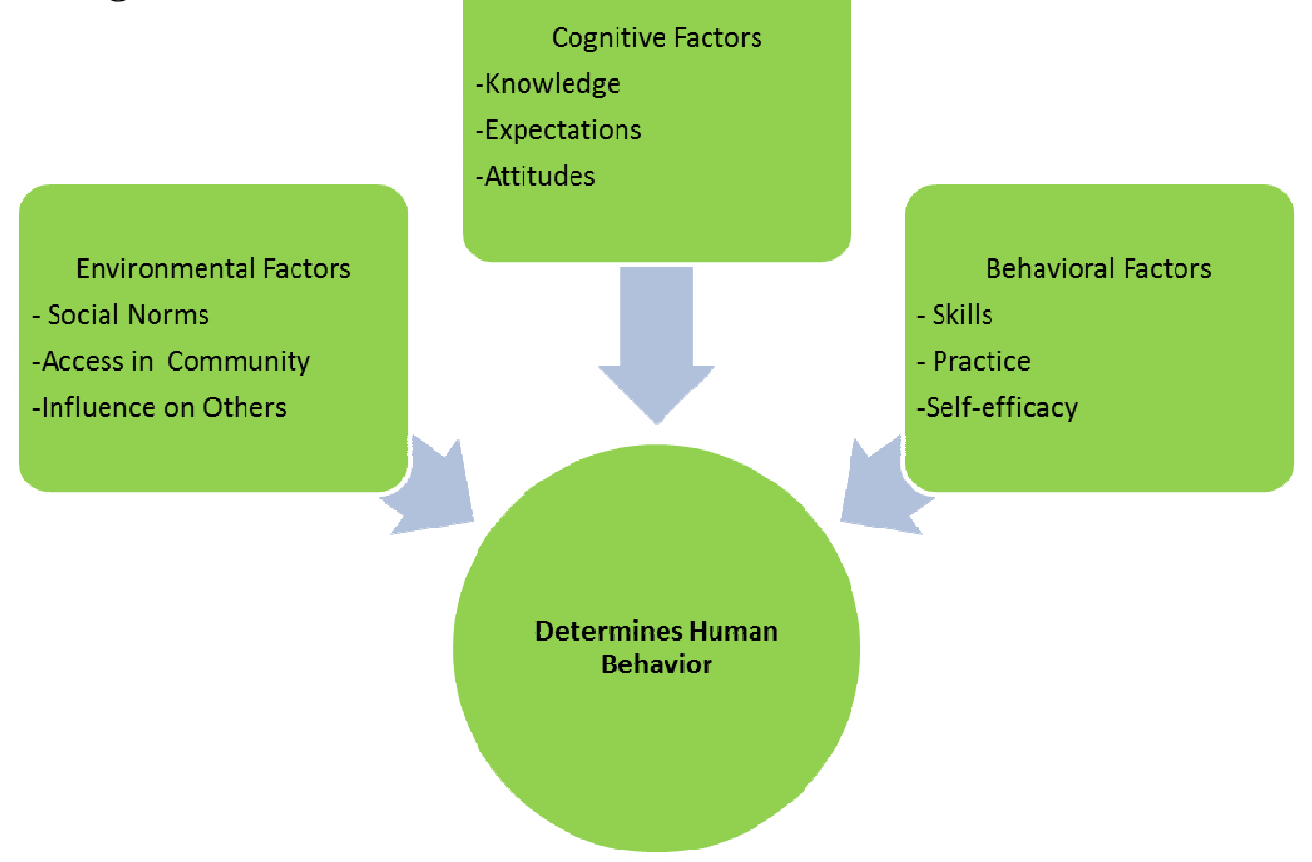

The ultimate goal of iCook4-H was to help the children learn by doing as well as get positive reinforcement and this is where the dyad model comes into play largely. By combining CBPR and keeping the SCT in mind, it has potential to be more successful and promote community empowerment. It allows the population being studied to see potential benefits from the research as opposed to feeling exploited. ${ }^{18}$ The best source of information about the community is the community. 


\section{Blood Pressure}

"The definition of hypertension in children and adolescents is based on the normative distribution of BP in healthy children. Blood pressure tables were developed on the Center for Disease Control (CDC) growth charts."4 The child's measured SBP and DBP are compared with the numbers provided in the table (boys or girls) according to the child's age and height percentile. The child is normotensive if the $\mathrm{BP}$ is below the 90th percentile. If the BP is equal to or above the 90th percentile, the BP measurement should be repeated at that visit to verify an elevated BP. BP measurements between the 90th and 95th percentiles indicate pre-hypertension and warrant reassessment and consideration of other risk factors. ${ }^{4}$

This is the current procedure for diagnosing hypertension in adolescents. In 2004 the standards for diagnosing pre-hypertension, stage 1 and stage 2 hypertension were updated. Children over the age of 3 years should have their BP measured at least once during every health care visit. Children under age 3 should have their BP measured in special circumstances. ${ }^{4}$ Elevated blood pressure should be seen on several different occasions before hypertension is diagnosed in a child.

In addition to the rise in pediatric and adolescent obesity, hypertension has also undergone an epidemiological shift. ${ }^{5}$ Hypertension in children used to be seen mainly in children with renal disease, but this health disparity is now often seen in an apparently healthy adolescent that suffer from obesity. ${ }^{5}$ Hypertension in youth can result in immediate health consequences and is shown to persist into adulthood resulting in a significant risk factor for cardiovascular disease (CVD). ${ }^{6}$ The current information indicates that early detection could have a positive impact on reducing health risks and improving cardiovascular health. ${ }^{6}$ Pediatricians and other health care providers need to stress the importance in blood pressure monitoring in the pediatric and adolescent 
population. Children with blood pressure levels above the $90^{\text {th }}$ percentile have 2.4 times higher risk of becoming hypertensive adults. ${ }^{8}$

Hypertension is often asymptomatic so routine measurement is key to an early diagnosis. The Fourth Report on Childhood Blood Pressure from the National Heart Lung and Blood Institute recommends that BP be measured routinely for all health care encounters in children aged 3 years and older. Without appropriate measurement and interpretation, increased BP cannot be recognized and necessary treatment strategies cannot be implemented. ${ }^{9}$ Accurate Blood pressure measurement can be difficult if cuff size is not appropriate. The cuff should encircle at least $80 \%$ of the upper arm but ideally $100 \%$. The best method in assessing BP is checking it 2-3 times with an automated device to eliminate human error. ${ }^{10}$ Once the blood pressure is measured it is important to interpret what it means accurately. ${ }^{9}$

The prevalence of hypertension and pre-hypertension among adolescents was determined by Karen L. McNiece et al. from 2003 to 2004. They conducted a cross-sectional assessment of blood pressure on 6790 adolescents (11-17 years) in Houston schools. "All students with a mean blood pressure in the hypertensive range had repeated measurements on up to two subsequent occasions if persistent to confirm the presence of hypertension as recommended." ${ }^{11}$ Prehypertension, stage 1 hypertension, and stage 2 hypertension all showed a statistically significant trend for increasing prevalence with increasing BMI percentile. The concerning issue is that more than $15 \%$ of this population fell into that at-risk category based on blood pressure values in this range or higher on at least one occasion. ${ }^{11}$ This study suggests that almost $20 \%$ of the adolescent population is already at risk for future cardiovascular disease and displays the importance of shaping an adequate and successful prevention program. Three Months seems to be adequate time to see an improvement in BP. $^{9}$ 


\section{Quality of Life}

The CDC has defined health related quality of life (HRQoL) as "an individual's or group's perceived physical and mental health over time." There are multiple forms of these surveys for different ages and populations that can come in short form surveys as well as more in depth depending on the type of information interested in collecting. The PedsQL (Pediatric Quality of Life Inventory) is a modular instrument for measuring health-related quality of life (HRQoL) in children and adolescents ages 2 to 18 . This scale allows researchers to get a look at the subjects own perception of quality of life and its possible impact when looking at different dimensions including; physical functioning, emotional functioning, social functioning, and school functioning. There are surveys designed for pediatric self-reported as well as parent proxy reported surveys when trying to assess pediatrics perception of QoL. When the pediatric population is able, it is important for them to take assessments because minimal agreement has been shown in some circumstances between self-reported and parent proxy reported surveys. ${ }^{12}$ These surveys are found to become more important to determining certain influences on QoL and its impact. ${ }^{13}$ This will help clinicians better help the patient by understanding what is affecting them emotionally in addition to physically.

With the increase in pediatric obesity it is important that we monitor QoL in this population. It has been shown that higher BMI in the overweight category is associated with lower Peds-QoL scores in the social and physical functioning categories. Children in the obesity category had decreased scores in the same with an addition to emotional functioning. ${ }^{14}$ When measuring quality of life there is only one expert and that is the participant taking the QoL survey. ${ }^{15}$

\section{Study Objectives}


The pilot study objective is to determine if a change was seen in BP, BMI and perspective of quality of life in youth at pre and post assessment after a 3 month culinary skills, family mealtime and physical activity focus intervention on 9-10 year olds. The second objective is to determine if there are correlations between BP and QoL after the three month intervention. 


\section{Chapter II}

\section{LITERATURE REVIEW}

\section{Blood Pressure and its Effects on Quality of Life in Children and Adolescents}

The rise in obesity in pediatrics and adolescents leads health professionals to have many concerns to what their future health status might hold. With obesity, come many other possible health conditions, including: hypertension, type 2 diabetes mellitus, dyslipidemia, as well as social and psychological problems. The main focus is to see if children and adolescents with prehypertension or hypertension will have a lower quality of life (QoL) compared to normotensive. A systematic search of the literature returned few results that looked specifically at blood pressure (BP), and its impact on QoL in children and adolescents so the search was broadened, looking at all age groups. A study done in Germany found individuals with hypertension had significantly higher QoL in family life, self-esteem and physical well-being compared with normotensive adolescents. This contradicts what is seen in adults in other studies where results showed that the Health Related Quality of Life (HRQoL) was worse in hypertensive patients than in normotensive. Labeling someone as prehypertensive had no negative effects on BP and Quality of Life (QoL) so should be used as a preventative tool. Lastly a BP was determined for optimal HRQoL and they found that for adults age $18-65$ was $125 / 75 \mathrm{~mm} \mathrm{hg}$ and for 65 and older is was $125 / 80 \mathrm{~mm} \mathrm{hg}$. Although this was determined, ultimately, each person needs to be treated on an individual basis to help reach optimal HRQoL.

Obesity is also a well-known risk factor in children and adolescents for hypertension. A study done in West Virginia, known as the Cardiac Project looked at whether obesity screening was an adequate measurement as a means of detecting higher risk for cardiovascular disease (CVD) in children and adolescents. They found that the odds of having high total cholesterol, low high 
density lipoprotein (HDL), and hypertension among obese children were 2 to 5 times those of nonoverweight children. Approximately $45 \%$ of the children in this study were overweight or obese. When obesity was used as a criterion, approximately $50-65 \%$ of children were found to have probable dyslipidemia and hypertension. ${ }^{20}$ Multiple risk factors need to be assessed when trying to determine if a child or adolescent has hypertension or is at risk for developing hypertension. Some of the known risk factors are ethnic and racial differences, weight and BMI status, hypertension, type 2 diabetes mellitus, and dyslipidemia. ${ }^{1}$ The goal of this review will be to focus on childhood and adolescent blood pressure data, and whether the impact on quality of life of these children and adolescents can be strongly determined.

A cross-sectional study conducted in Brazil tried to determine the best risk factors to look for when trying to monitor for pediatric hypertension. This study looked at one private school and one public school, which could be an indicator of socio economic status. This study used the Quality of Urban Life (QUL); this is based on family income, health conditions, social assistance, education, and housing conditions. Of 307 white children, $21.5 \%$ were overweight or obese compared to $14.5 \%$ non-white children being overweight or obese. The systolic blood pressure (SBP) was significantly higher in school-aged white children $(\mathrm{p}<0.001)$, in children with a high QUL and in children with a high body mass index (BMI). The diastolic pressure was significantly higher in white children and in children with a high QUL. This shows that the QUL could be used as a possible risk factor for increased blood pressure in children. ${ }^{7}$

In contrast to the last study, many studies have been conducted on high risk populations for CVD, such as African American children and Mexican children. ${ }^{21}{ }^{22}$ CVD is one of the main causes of reduced quality of life among African Americans with hypertension being one of the risk factors. ${ }^{23}$ In a study with Mexican children of low socioeconomic status, $22.8 \%$ had mixed 
hypertension which is a high systolic and diastolic number. $3.6 \%$ had systolic hypertension and $14.2 \%$ diastolic hypertension. The prevalence of hypertension in the sample of Mexican children is high, with waist circumference (WC) being the main factor associated with systolic pressure and higher total fat intake being related to diastolic hypertension. ${ }^{21}$ The statistical analysis conducted on a cohort of African American children with a high BMI showed that measuring WC is a strong predictor of cardiovascular disease (CVD). The overall conclusion from this study is that WC is either as good as or better than BMI in predicting CVD risk using these markers. ${ }^{22}$ In contrast, a meta-analysis completed by Friedemanm et al. found that having a BMI outside of normal range significantly worsens risk parameters for CVD in relatively healthy school aged children. ${ }^{24}$ Overall WC, BMI, and QUL have all been shown to be beneficial markers in predicting CVD risk.

Kalarchian et al. researched a program that's main focus was to treat severe pediatric obesity. The children were between the ages of 8 and 12 and the average BMI percentile for age and gender was 99.18. The families were randomly assigned to the intervention which used family based treatment or the usual care. The intervention had 20 group meetings in the first 6 months. The results showed a significant decrease in blood pressure in the intervention group but not in the usual care group. There was also an average decrease of $8.2 \%$ overweight in the intervention. ${ }^{25}$

\section{Quality of Life in Children and Adolescence}

The question is does the prevalence of hypertension among the pediatric population have an impact on their perception of quality of life? Few studies have looked at this, but there are some that look at Peds-QL with weight maintenance or weight loss in adolescents and its impact on the quality of life. Another important factor to keep in mind is increased health disparities in different ethnic populations. A study looking at racial and ethnic health disparities among fifth-graders found significantly lower differences in health status and QoL comparing white non-Latinos to 
black and Latino children. They found that the black and Latino children reported significantly lower with fair to poor health, psychological quality of life in past 30 days, and physical quality of life in past 30 days $(\mathrm{p}<0.001){ }^{26}$

Angela Berendes et al. conducted research on adolescents, ages 11-17 with hypertensive blood pressure to determine if it is linked a lower quality of life and higher distress. After taking the BP, HRQoL, and a Measure of Distress questionnaire on 7688 adolescents in Germany, the results are quite shocking. Individuals with hypertension had significantly higher QoL in "family Life" ( $\mathrm{P}=.011)$, "self-esteem" ( $\mathrm{p}=.028)$, and "physical well-being" ( $\mathrm{p}=.001)$ compared with normotensive adolescents. The parents confirmed the same thing as the adolescents. This is the opposite of what has been suggested. The measure of distress scores from parents and children revealed that the hypertensive children were less active than normotensive $(\mathrm{p}<0.005)$

The authors provided possible explanations as to why these scores were the opposite of what one would expect. Some adolescents may be more focused on reaching goals that get them recognized so are more successful in their school careers than others which may increase their level of stress and result elevated BP but lead to better self-esteem and QoL. Trying to be unaware of ones emotions may lead to better self-ratings of distress and QoL, and repressed emotions might at the same time lead to elevations in BP. Either way, none of these explanations have been proven hence more research in this area is needed. ${ }^{27}$ Table 1 compares all of the studies discussed that look specifically at blood pressure and its impact on quality of life. The German study had a large number of participants, but the results were different than the other studies. The German study also had a large age range, which could contribute to variability. 
Table 1.0 Comparison of BP and its Effect on HRQoL

\begin{tabular}{|l|c|c|c|c|}
\hline \multicolumn{5}{|c|}{ Comparison of BP and its Effect on HRQoL } \\
\hline Study & $\begin{array}{c}\text { Age Examined in } \\
\text { Years }\end{array}$ & $\begin{array}{c}\text { Number of } \\
\text { Individuals }\end{array}$ & $\begin{array}{c}\text { Improvement in } \\
\text { BP or already } \\
\text { Normotensive }\end{array}$ & $\begin{array}{c}\text { Improvement } \\
\text { in HRQoL }\end{array}$ \\
\hline Helen Croker et al. & $8-12$ years of age & 72 & Yes & Yes \\
\hline Angela Bernendes et al. & Ages 11-17 & 7688 & No & No \\
\hline Jen-Chen Tsai et al. & $20-60$ years of age & 102 & Yes & Yes \\
\hline $\begin{array}{l}\text { Josiane Lima de Gusmao } \\
\text { et al. }\end{array}$ & $54 \geq 8$ years & 77 & Yes & Yes \\
\hline Didem Arslantas, et al. & $\geq 50$ years of age & 1193 & Yes & Yes \\
\hline
\end{tabular}

Kalarchian et al. looked at the feasibility as well as the preliminary outcomes of a program focusing on childhood obesity with one of its main outcome focuses on health related quality of life (HRQoL). This study had 155 children and their parent/guardian. The parent and child would attend the sessions together over the six months with 24 sessions total and six of them were face to face. The focus of the treatment was the child with emphasis on the parent to help support the child in the weight management. The overall sample experienced a significant percentage reduction in weight $(\mathrm{p}=0.001)$ after 6 months with $8 \%$ fewer children above the $99^{\text {th }}$ percentile at 24 weeks and $10 \%$ fewer children were in obese category at 24 wks. With the pre-test child-report of HRQoL it was worse in healthy children and adolescents across multiple domains. At 6 months the children experienced significant improvements in HRQoL. These improvements in HRQoL were greater in the younger group with $\mathrm{p}<0.001$ compared to $\mathrm{p}=0.03$, but were significant in both age groups. The children reported the biggest improvement in emotional functioning whereas the parents believed the biggest improvement in their child's HRQoL was in physical health. These 
findings show clinically significant outcomes, including improvements in weight status as well as HRQoL after these 24 sessions. $^{28}$

Another study that was done in the United Kingdom (UK) used family base behavioral therapy (FBBT) with a socially diverse population. The children were randomized into the FBBT group or the control group. A pre and post assessments at 12 months was taken and it looked at anthropometric measures as well as psychosocial measures. There were significant BMI changes and a significant reduction in systolic BP. There were improvements in QoL and eating attitudes but they were not found to be significant. The FBBT group showed a significant reduction in systolic BP and improvements in QoL and eating attitudes with no significant change in the control group. No significant differences were found when the two groups were compared with independent t-tests or Mann-Whitney test (continuous variables) or chi-squared test (categorical variables). ${ }^{29}$ This shows that FBBT could be used when trying to improve QoL and BP.

\section{Blood Pressure, Quality of Life, and Adults >18 years}

The lack of information pertaining to children's blood pressure and the impact on quality of life needs to be looked into further. There are very few studies that specifically look at the two. With the increased risk of developing hypertension when overweight or obese the impact on quality of life is still unknown. ${ }^{30}$ Given that there is little information pertaining to children, there is some research that looks into BP and its potential impact on QoL with adults. Jen-Chen Tsai et al. discovered a correlation in ages 20-60 that HRQoL is lower in hypertensive patients than normotensive and the reason behind this is still unknown but the question has been posed if it was

because they were aware they had hypertension. ${ }^{31}{ }^{32}$ This is the opposite of what was shown in adolescents in the German study which showed that QoL was not affected by BP. ${ }^{27}$ 
A study conducted in a semi-rural area of western Turkey tried to determine the effects on the HRQoL that hypertension among individuals aged 50 years and over can have. This was a population based cross sectional study on 1193 individuals. The HRQoL and BP were determined as well as a questionnaire determining health history, socio economic status and, demographics were taken with face to face interview. The BMI was also calculated. What they found was the HRQoL was worse in hypertensive patients than in normotensive in this study $(\mathrm{p}<=0.001)$. Again, in a different population and age range the opposite of what was found in the German adolescent study was discovered. ${ }^{27}$

A study that looked specifically at QoL in hypertensive patients found very similar results to what Jen-Chen Tsai et al. found. This research design looked at people with hypertension that had complications opposed to those that had no complications. The hypertensive patients without complications had to have SBP greater than or equal to $140 \mathrm{mmhg}$, and a DBP less than 110mmh, either undergoing treatment or not getting treatment, and no target-organ damage. The hypertensive patients with complications had to have a DBP greater than or equal to $110 \mathrm{~mm} \mathrm{hg}$, also undergoing treatment or not, and had clinically marked target-organ damage. In the beginning of the study there was no significant difference between the two groups. They did find however, that normotensive patients had a significantly higher HRQoL in the functional capacity, bodily pain, and vitality domains and a change in one dimension for QoL can impact another dimension. ${ }^{7}$ The studies conducted on adults have been conclusive in determining that as BP worsens so does QoL.

To determine if labeling someone with prehypertension could have an impact on their QoL, Tanya M Spruill et al. tried to establish if it is beneficial to their health and to their QoL. The label prehypertension was developed to try and help patients become more aware of their increased risk 
for hypertension. The question was discussed earlier if telling someone they are hypertensive automatically affects that person's perception of their quality of life. ${ }^{31}$ This study tries to determine if it that holds some truth. There were two randomized groups, one of the groups was informed of their risk, but was not specifically told that they have prehypertension. The other group was told that they were at risk and is prehypertensive. Both groups were given the HRQoL questionnaires at baseline and 3 months. The results from this study showed that prehypertension labeling did not negatively affect patients. It did not negatively affect blood pressure or their QoL. ${ }^{32}$

The final question assessed was to determine if there is a specific BP value for optimal quality of life? A study by Monika Zygmuntowicz et al. tried to find that out. This study looked at 11,498 white patients ages 18-65 and older than 65 years old. The 18-65 were called the "younger" group and the greater than 65 was the "older". They all had to of been treated continuously for hypertension for at least 12 months. These participants HRQoL was assessed using the 12-Item Short Form Health Survey. They found that for SBP to be associated with an optimal physical component summary (PCS) in both the young and old group it needed to be $125 \mathrm{~mm} \mathrm{hg}$. For the mental component summary (MCS), it was $8 \mathrm{~mm}$ hg higher in the older group. The DBP associated with optimal PCS and MCS scores was $80 \mathrm{~mm}$ hg in the older group and $75 \mathrm{~mm}$ hg in the younger group. Ultimately, BP values associated with optimal HRQoL increase with the number of drugs which reflects the severity of the disease so each person needs to be treated on an individual basis to help reach optimal HRQoL. ${ }^{33}$

Overall, research in pediatric population has been inconclusive but in the adult population it is shown that as BP worsens so does QoL. Due to the increase in adolescent and pediatric obesity, there is also an increase in multiple health complications. Pediatric hypertension is one of the possible complications that can have detrimental effects. Hypertension in children and adolescents 
persist into adulthood and is a significant risk factor for CVD, which is the number one killer in the United States. With very little data to look at in the adolescent population and the conflicting data between adolescents and adults, more research is greatly needed. Research done on the adult population has found that normotensive patients had a significantly higher HRQoL in the functional capacity, bodily pain, and vitality domains where as in a study on adolescent's individuals with hypertension had significantly higher QoL compared to the normotensive adolescents. ${ }^{27}$ Studies have also found that prehypertension labeling did not negatively affect patients with their BP or their QoL, suggesting that earlier detection can still be used to help enforce a positive impact on an individual's health. ${ }^{32}$ In conclusion, the lack of research on children and adolescence blood pressure and its impact on QoL is an area that needs more research When looking at this data it is important to remember that children and adolescents are different from adults and the more research we do on this population, the closer we can become in tackling a possible epidemic in the near future. 


\section{Chapter III \\ Journal Article Submission}

\section{Abstract}

As childhood obesity rates climb, health professionals' concern for the well-being of children and adolescents increases. Obesity creates many other possible health conditions, including:

hypertension, type 2 diabetes mellitus, dyslipidemia, as well as social and psychological problems. Children and adolescents with prehypertension or hypertension may have a lower quality of life (QoL) compared to normotensive individuals. An investigation of the current literature returned few results specifically targeting blood pressure (BP) and its impact on QoL in children and adolescents. Due to the limited outcome, the search was then broadened to all age groups. A study done in Germany, found individuals with hypertension had significantly higher QoL in family life, self-esteem and physical well-being compared with normotensive adolescents. This contradicts what was seen in adults in other studies, where results showed that the Health Related Quality of Life (HRQoL) was worse in hypertensive patients than in normotensive. Labeling individuals as prehypertensive was found to have no negative affects on BP and Quality of Life (QoL) which could be used as a preventative tool. Lastly, a BP was determined for optimal HRQoL in adults age $18-65$ was $125 / 75 \mathrm{~mm} \mathrm{hg}$ and for 65 and older is was $125 / 80 \mathrm{~mm} \mathrm{hg}$. Although this was determined, ultimately, each person needs to be treated on an individual basis to help reach optimal HRQoL.

Keywords: Blood Pressure, Quality of Life, Youth, Children 
Due to the rates of obesity increasing, it is important that Americans focus on promoting healthier lifestyles. The US Government has increased funding to programs to help with this initiative in adolescence; for example "Let's Move" campaign that was launched by first lady Michelle Obama. In the United States, heart disease is the leading cause of death. (CDC/National Center for Health Statistics, October 19, 2012) Obesity has become an increasingly large problem in children and adolescents; it is potentially leading to more co-morbidities. Among children 2-5 years old, obesity prevalence increased from 5\% to $12.4 \%$; among children 6-11 years old, it increased from $6.5 \%$ to $17 \%$; and among adolescents $12-19$ years old, it increased from $5 \%$ to 17.6\%. (CDC grand rounds: Childhood obesity in the united states.2011) Some possible comorbidities related to obesity include: hypertension, type 2 diabetes mellitus, dyslipidemia, as well as social and psychological problems. (Obesity evaluation and treatment: Expert committee recommendations1998)

In addition to the rise in pediatric and adolescent obesity, hypertension has also undergone an epidemiological shift. (Sorof \& Daniels, 2002) Hypertension in children used to be seen mainly in children with renal disease, but this health disparity is now often seen in an apparently healthy adolescent that suffers from obesity. (Sorof \& Daniels, 2002) Hypertension in pediatric patients can result in immediate health consequences and is shown to persist into adulthood, resulting in a significant risk factor for CVD. (Cromwell, Munn, \& Zolkowski-Wynne, 2005) (Garcia et al., 2004) The current information indicates that early detection could have a positive impact on reducing health risks and improving cardiovascular health. (Cromwell et al., 2005) Pediatricians and other health care providers need to stress the importance in blood pressure monitoring in the pediatric and adolescent population. Children with blood pressure levels above the $90^{\text {th }}$ percentile have 2.4 times higher risk of becoming hypertensive adults. (Mahoney, Clarke, Burns, \& Lauer, 
1991) The best method in assessing BP is checking it 2-3 times with an automated device. (Chen, Wang, Appel, \& Mi, 2008)

Obesity is a well-known risk factor in children and adolescents for hypertension. A study done in West Virginia, known as the "Cardiac Project," determined that obesity screening is an adequate measurement tool for detecting higher risk for cardiovascular disease (CVD) in children and adolescents. The Cardiac Project found that the odds of having high total cholesterol, low high density lipoprotein (HDL), and hypertension among obese children are two to five times those of non-overweight children. Approximately $45 \%$ of the children in this study were overweight or obese. When obesity was used as a criterion, approximately $50-65 \%$ of children were found to have probable dyslipidemia and hypertension. (Demerath et al., 2003) Multiple risk factors need to be assessed when trying to determine if a child or adolescent has hypertension or is at risk for developing hypertension. Some of the known risk factors are ethnic and racial differences, weight and BMI status, hypertension, type 2 diabetes mellitus, and dyslipidemia. (CDC/National Center for Health Statistics, October 19, 2012) The goal of this review is to focus on childhood and adolescent blood pressure data, and whether the impact on quality of life of these children and adolescents can be strongly determined.

A cross-sectional study done in Brazil tried to determine the best risk factors to look at when trying to monitor for pediatric hypertension. This study looked at one private school and one public school; this could be an indicator of socio economic status. This study used the Quality of Urban Life (QUL) which is based on family income, health conditions, social assistance, education, and housing conditions. It was determined, that of the 307 white children, $21.5 \%$ were overweight or obese compared to $14.5 \%$ non-white children being overweight or obese. The systolic blood pressure (SBP) was significantly higher in school-aged white children $(\mathrm{p}<0.001)$, in 
children with a high QUL and in children with a high body mass index (BMI). The diastolic pressure was also significantly higher in white children and in children with a high QUL. This study shows that the QUL could be used as a possible risk factor for increased blood pressure in children. (Garcia et al., 2004)

In contrast to the last study, many studies have been conducted on high risk populations for CVD, such as African American children and Mexican children. . (Colin-Ramirez et al., 2009) (Raman, Sharma, Fitch, \& Fleming, 2010) CVD is one of the main causes of reduced quality of life among African Americans with hypertension being one of the risk factors. (Gittner, Hassanein, \& Murphy, 2007) In a study with Mexican children of low socioeconomic status, $22.8 \%$ had mixed hypertension which is a high systolic and diastolic number. $3.6 \%$ had systolic hypertension and 14.2\% diastolic hypertension. The prevalence of hypertension in the sample of Mexican children was high. Waist circumference (WC) was determined as the main factor associated with systolic pressure and higher total fat intake being related to diastolic hypertension. . (Colin-Ramirez et al., 2009) The statistical analysis from a cohort of African American children with a high BMI showed that measuring WC was a strong predictor of cardiovascular disease (CVD). The overall conclusion of this study was that WC is either as good as or better than BMI in predicting CVD risk... (Raman et al., 2010) In contrast, a meta-analysis done by Friedemanm et al. found that having a BMI outside of normal range, significantly worsens risk parameters for CVD in relatively healthy school aged children. (Claire Friedemann et al., 2012)

Kalarchian et al. did a study on a program that's main focus was to treat severe pediatric obesity. The children were between the ages of 8 and 12; the average BMI percentile for age and gender was 99.18. The families were randomly assigned to the intervention, which used family based treatment or the usual care. The intervention had 20 group meetings in the first 6 months. The 
results showed a significant decrease in blood pressure in the intervention group, but not in the usual care group. There was also an average decrease of $8.2 \%$ overweight in the intervention. (Kalarchian et al., 2009)

The PedsQL (Pediatric Quality of Life Inventory) is a modular instrument for measuring healthrelated quality of life (HRQoL) in children and adolescents ages 2 to 18 . This scale allows researchers to get a look at the subjects own perception of quality of life. The question is, "does the prevalence of hypertension among the pediatric population have an impact on their perception of quality of life?" Few studies have looked at this, but there are some that look at PedsQL with weight maintenance or weight loss in adolescents and its impact on the quality of life. Another important factor to examine was the increased health disparities in different ethnic populations. A study looking at racial and ethnic health disparities among fifth-graders found significantly lower differences in health status and QoL comparing white non-Latinos to black and Latino children. They found that the black and Latino children reported significantly lower with fair to poor health, psychological quality of life in past 30 days, and physical quality of life in past 30 days $(\mathrm{p}<0.001)$. (Schuster et al., 2012)

Angela Berendes et al. examined adolescents, ages 11-17 with hypertensive blood pressure to determine if it is linked a lower quality of life and higher distress. After taking the BP, HRQoL, and a Measure of Distress questionnaire on 7688 adolescents in Germany, the results are quite shocking. Individuals with hypertension had significantly higher QoL in "family Life" (P=.011), "self-esteem" ( $p=.028)$, and "physical well-being" ( $p=.001)$ compared with normotensive adolescents. The parents confirmed the same thing as the adolescents; this is the opposite of what has been suggested. The measure of distress scores from parents and children, revealed that the hypertensive children were less active than normotensive $(\mathrm{p}<0.005)$ 
The authors provided some possible explanations as to why these scores were the opposite of what one would expect. Some adolescents may be more focused on reaching goals that get them recognized; therefore, they are more successful in their school careers than others, which may increase their level of stress and result elevated BP, but lead to better self-esteem and QoL. Trying to be unaware of one's emotions may lead to better self-ratings of distress and QoL, and repressed emotions might at the same time lead to elevations in BP. Either way, none of these explanations have been proven, so there is more research needed in this area. (Berendes, Meyer, Hulpke-Wette, \& Herrmann-Lingen, 2013) Table 1 shows all of the studies discussed that look specifically at blood pressure and its impact on quality of life. The German study had a large number of participants, but the results were different than the other studies. "Insert Table 1 Here"

Kalarchian et al. looked at the feasibility as well as the preliminary outcomes of a program focusing on childhood obesity with one of its main outcome focuses on health related quality of life (HRQoL). This study had 155 children and their parent/guardian. The parent and child would attend the sessions together over the six months with 24 sessions; a total and six of sessions were face to face. The focus of the treatment was the child, with emphasis on the parent to help support the child in the weight management. The overall sample experienced a significant percentage reduction in weight ( $\mathrm{p}=0.001)$ after 6 months with $8 \%$ fewer children above the $99^{\text {th }}$ percentile at 24 weeks and $10 \%$ fewer children were in obese category at 24 wks. With the pre-test child-report of HRQoL it was worse in healthy children and adolescents across multiple domains. At 6 months, the children experienced significant improvements in HRQoL. These improvements in HRQoL were greater in the younger group with $p<0.001$ compared to $p=0.03$, but were significant in both age groups. The children reported the biggest improvement in emotional functioning, whereas the 
parents believed the biggest improvement in their child's HRQoL was in physical health. These findings show clinically significant outcomes, including improvements in weight status as well as HRQoL. (Foster et al., 2012)

Another study that was done in the United Kingdom (UK) used family base behavioral therapy (FBBT) with a socially diverse population. The children were randomized into the FBBT group or the control group. A pre and post assessments at 12 months was taken and it examined anthropometric measures as well as psychosocial measures. There were significant BMI changes and a significant reduction in systolic BP. There were improvements in QoL and eating attitudes, but they were not found to be significant. The FBBT group showed a significant reduction in systolic BP and improvements in QoL and eating attitudes with no significant change in the control group. No significant differences were found when the two groups were compared with independent t-tests or Mann-Whitney test (continuous variables) or chi-squared test (categorical variables). (Croker et al., 2012)

The lack of information pertaining to children's blood pressure and the impact on quality of life needs to be examined further. There are very few studies that specifically look at the two. With the increased risk of developing hypertension when overweight or obese, the impact on quality of life is still unknown. (Ogden et al., 1997) Since there is little information pertaining to children, much of the research examined adults. Jen-Chen Tsai et al. found a correlation in ages 20-60, that HRQoL is lower in hypertensive patients than normotensive. The reason behind this is still unknown. The question has been posed if it was because they were aware they had hypertension. (Tsai et al., 2004) (Spruill et al., 2013) This is the opposite of what was shown in adolescents in the German study. (Berendes et al., 2013) 
A study conducted in a semi-rural area of western Turkey tried to determine the effects on the that hypertension among individuals aged 50 years and over can have. This was a population based cross sectional study on 1193 individuals. The HRQoL, BP were determined as well as a questionnaire determining health history, socio economic status and, demographics with face to face interview were taken. The BMI was also calculated. What they found was the HRQoL was worse in hypertensive patients than in normotensive in this study $(\mathrm{p}<=0.001)$. Again, in a different population and age range the opposite of what was found in the German adolescent study was discovered. (Berendes et al., 2013)

A study that looked specifically at QoL in hypertensive patients found very similar results to what Jen-Chen Tsai et al. found. This research design looked at people with hypertension that had complications and that had no complications. The hypertensive patients without hypertension had to have SBP greater than or equal to $140 \mathrm{mmhg}$, and a DBP less than $110 \mathrm{mmhg}$, either undergoing treatment or not getting treatment, and no target-organ damage. The hypertensive patients with complications had to have a DBP greater than or equal to $110 \mathrm{~mm} \mathrm{hg}$, also undergoing treatment or not, and had clinically marked target-organ damage. In the beginning of the study there was no significant difference between the two groups. They did find however, that normotensive patients had a significantly higher HRQoL in the functional capacity, bodily pain, and vitality domains and a change in one dimension for QoL can impact another dimension. (Garcia et al., 2004) To determine if labeling someone with prehypertension could have an impact on their QoL, Tanya M Spruill et al. tried to determine if it is beneficial to their health and to their QoL.

Prehypertension was developed to try and help patients become more aware of their increased risk for hypertension. The question was discussed earlier if telling someone they are hypertensive automatically affects that person's perception of their quality of life. (Tsai et al., 2004) This study 
tries to determine if it that holds some truth. There were two randomized groups; one of the groups were informed of their risk, but was not specifically told that they have prehypertension. The other group was told that they were at risk and is prehypertensive. Both groups were given the HRQoL questionnaires at baseline and 3 months. The results from this study showed that prehypertension labeling did not negatively affect patients. It did not negatively affect blood pressure or their QoL. (Spruill et al., 2013)

The final question assessed was to determine if there is a specific BP value for optimal quality of life. A study by Monika Zygmuntowicz et al. examined 11,498 white patients ages 18-65 and older than 65 years old. The 18-65 were called the "younger" group and the greater than 65 was the "older". They all had to of been treated continuously for hypertension for at least 12 months. These participants HRQoL was assessed using the 12-Item Short Form Health Survey. They found that for SBP to be associated with an optimal physical component summary (PCS) in both the young and old group it needed to be $125 \mathrm{~mm}$ hg. For the mental component summary (MCS), it was $8 \mathrm{~mm} \mathrm{hg} \mathrm{higher} \mathrm{in} \mathrm{the} \mathrm{older} \mathrm{group.} \mathrm{The} \mathrm{DBP} \mathrm{associated} \mathrm{with} \mathrm{optimal} \mathrm{PCS} \mathrm{and} \mathrm{MCS} \mathrm{scores}$ was $80 \mathrm{~mm} \mathrm{hg}$ in the older group and $75 \mathrm{~mm}$ hg in the younger group. Ultimately, BP values associated with optimal HRQoL increase with the number of drugs. This reflects the severity of the disease, which proves that each person needs to be treated on and individual basis to help reach optimal HRQoL. (Zygmuntowicz, Owczarek, Elibol, Olszanecka-Glinianowicz, \& Chudek, 2013) Due to the increase in adolescent and pediatric obesity, there is also an increase in multiple health complications. Pediatric hypertension is one of the possible complications that can have detrimental effects. Hypertension in children and adolescents persist into adulthood and is a significant risk factor for CVD, which is the number one killer in the United States. The lack of research on children and adolescence blood pressure and its impact on QoL is a huge area that 
needs more research. With very little data to examine in the adolescent population and the conflicting data between adolescents and adults, more research is greatly needed. Research done on the adult population has found that normotensive patients had a significantly higher HRQoL in the functional capacity, bodily pain, and vitality domains where as in a study on adolescent individuals with hypertension had significantly higher QoL compared to the normotensive adolescents. (Garcia et al., 2004)(Berendes et al., 2013) Studies have also found that prehypertension labeling did not negatively affect patients with their BP or their QoL, suggesting that earlier detection can still be used to help enforce a positive impact on an individual's health. (Spruill et al., 2013) When looking at this data it is important to remember that children and adolescents are different from adults and the more research we do on this population, the closer we can become in tackling a possible epidemic in the near future.

\section{References}

Berendes, A., Meyer, T., Hulpke-Wette, M., \& Herrmann-Lingen, C. (2013). Association of elevated blood pressure with low distress and good quality of life: Results from the nationwide representative German health interview and examination survey for children and adolescents. Psychosomatic Medicine, 75(4), 422-428. doi:10.1097/PSY.0b013e31828ef0c2

CDC grand rounds: Childhood obesity in the United States. (2011). MMWR: Morbidity \& Mortality Weekly Report, 60(2), 42-46. Retrieved from http://search.ebscohost.com/login.aspx?direct=true\&db=c8h\&AN=2010918986\&site=ehost$\underline{\text { live }}$

CDC/National Center for Health Statistics. (October 19, 2012). Leading causes of death. Retrieved 10/31, 2012, from http://www.cdc.gov/nchs/fastats/lcod.htm 
Chen, X., Wang, Y., Appel, L. J., \& Mi, J. (2008). Impacts of measurement protocols on blood pressure tracking from childhood into adulthood: A metaregression analysis. Hypertension, 51(3), 642-649. doi:10.1161/HYPERTENSIONAHA.107.102145;

10.1161/HYPERTENSIONAHA.107.102145

Claire Friedemann, Carl Heneghan, Kamal Mahtani, Matthew Thompson, Rafael Perera, \& Alison M Ward. (2012). Cardiovascular disease risk in healthy children and its association with body mass index: Systematic review and meta-analysis. Bmj, 345 doi:10.1136/bmj.e4759

Colin-Ramirez, E., Castillo-Martinez, L., Orea-Tejeda, A., Villa Romero, A. R., Vergara Castaneda, A., \& Asensio Lafuente, E. (2009). Waist circumference and fat intake are associated with high blood pressure in Mexican children aged 8 to 10 years. Journal of the American Dietetic Association, 109(6), 996-1003. doi:10.1016/j.jada.2009.03.011; 10.1016/j.jada.2009.03.011

Croker, H., Viner, R. M., Nicholls, D., Haroun, D., Chadwick, P., Edwards, C., . . Wardle, J. (2012). Family-based behavioural treatment of childhood obesity in a UK National Health Service setting: Randomized controlled trial. International Journal of Obesity (2005), 36(1), 16-26. doi:10.1038/ijo.2011.182

Cromwell, P. F., Munn, N., \& Zolkowski-Wynne, J. (2005). Evaluation and management of hypertension in children and adolescents (part one): Diagnosis. Journal of Pediatric Health Care, 19(3), 172-175. doi:10.1016/j.pedhc.2005.02.005

Demerath, E., Muratova, V., Spangler, E., Li, J., Minor, V. E., \& Neal, W. A. (2003). Schoolbased obesity screening in rural Appalachia. Preventive Medicine, 37(6), 553-560. doi:10.1016/j.ypmed.2003.09.013 
Foster, G. D., Sundal, D., McDermott, C., Jelalian, E., Lent, M. R., \& Vojta, D. (2012).

Feasibility and preliminary outcomes of a scalable, community-based treatment of childhood obesity. Pediatrics, 130(4), 652-659. doi:10.1542/peds.2012-0344

Garcia, F. D., Terra, A. F., Queiroz, A. M., Correia, C. A., Ramos, P. S., Ferreira, Q. T., . .

Oliveira, E. A. (2004). [Evaluation of risk factors associated with increased blood pressure in children]. Jornal De Pediatria, 80(1), 29-34. Retrieved from http://search.ebscohost.com/login.aspx?direct=true \&db=cmedm\&AN=14978546\&site=ehos $\underline{\text { t-live }}$

Gittner, L. S., Hassanein, S. E., \& Murphy, P. J. (2007). Church-based heart health project: Health status of urban African Americans. The Permanente Journal, 11(3), 21-25.

Retrieved from http://search.ebscohost.com/login.aspx?direct=true \&db=cmedm\&AN=21461108\&site=ehos $\underline{\mathrm{t}-\text { live }}$

Kalarchian, M. A., Levine, M. D., Arslanian, S. A., Ewing, L. J., Houck, P. R., Cheng, Y., . . Marcus, M. D. (2009). Family-based treatment of severe pediatric obesity: Randomized, controlled trial. Pediatrics, 124(4), 1060-1068. doi:http://dx.doi.org/10.1542/peds.2008$\underline{3727}$

Mahoney, L. T., Clarke, W. R., Burns, T. L., \& Lauer, R. M. (1991). Childhood predictors of high blood pressure. American Journal of Hypertension, 4(11), 608S-610S.

Obesity evaluation and treatment: Expert committee recommendations (1998). American Academy of Pediatrics. Retrieved from http://search.ebscohost.com/login.aspx?direct=true\&db=hch\&AN=1073200\&site=ehost-live 
Ogden, C. L., Troiano, R. P., Briefel, R. R., Kuczmarski, R. J., Flegal, K. M., \& Johnson, C. L. (1997). Prevalence of overweight among preschool children in the United States, 1971 through 1994. Pediatrics, 99(4), e1-e1. doi:10.1542/peds.99.4.e1

Raman, A., Sharma, S., Fitch, M. D., \& Fleming, S. E. (2010). Anthropometric correlates of lipoprotein profile and blood pressure in high BMI African American children. Acta Paediatrica (Oslo, Norway : 1992), 99(6), 912-919. doi:10.1111/j.1651-2227.2009.01639.x; 10.1111/j.1651-2227.2009.01639.x

Schuster, M. A., Elliott, M. N., Kanouse, D. E., Wallander, J. L., Tortolero, S. R., Ratner, J. A., . . Banspach, S. W. (2012). Racial and ethnic health disparities among fifth-graders in three cities. New England Journal of Medicine, 367(8), 735-745. Retrieved from $\underline{\text { http://search.ebscohost.com/login.aspx } ? \text { direct=true\&db=lbh\&AN=20123277573\&site=ehost }}$ -live; http://www.nejm.org/medical-index

Sorof, J., \& Daniels, S. (2002). Obesity hypertension in children: A problem of epidemic proportions. Hypertension, 40(4), 441-447.

Spruill, T. M., Feltheimer, S. D., Harlapur, M., Schwartz, J. E., Ogedegbe, G., Park, Y., \& Gerin, W. (2013). Are there consequences of labeling patients with prehypertension? an experimental study of effects on blood pressure and quality of life. Journal of Psychosomatic Research, 74(5), 433-438. doi:10.1016/j.jpsychores.2013.01.009

Tsai, J., Yang, H., Wang, W., Hsieh, M., Chen, P., Kao, C., . . Chan, P. (2004). The beneficial effect of regular endurance exercise training on blood pressure and quality of life in patients with hypertension. Clinical and Experimental Hypertension (New York, N.Y.: 1993), 26(3), 255-265. Retrieved from 
http://search.ebscohost.com/login.aspx?direct=true \&db=cmedm\&AN=15132303\&site=ehos

$\underline{\mathrm{t}-\text { live }}$

Zygmuntowicz, M., Owczarek, A., Elibol, A., Olszanecka-Glinianowicz, M., \& Chudek, J.

(2013). Blood pressure for optimal health-related quality of life in hypertensive patients.

Journal of Hypertension, 31(4), 830-839. doi:10.1097/HJH.0b013e32835ebdd7

\begin{tabular}{|l|c|c|c|c|}
\hline Table 1. Comparison of BP and its Effect on HRQoL \\
\hline Study & $\begin{array}{c}\text { Age Examined } \\
\text { in Years }\end{array}$ & $\begin{array}{c}\text { Number of } \\
\text { Individuals }\end{array}$ & $\begin{array}{c}\text { Improvement in } \\
\text { BP or already } \\
\text { Normotensive }\end{array}$ & $\begin{array}{c}\text { Improvement in } \\
\text { HRQoL }\end{array}$ \\
\hline $\begin{array}{l}\text { Helen Croker et } \\
\text { al. }\end{array}$ & $\begin{array}{c}8-12 \text { years of } \\
\text { age }\end{array}$ & 72 & Yes & Yes \\
\hline $\begin{array}{l}\text { Angela } \\
\text { Bernendes et al. }\end{array}$ & Ages 11-17 & 7688 & No & No \\
\hline $\begin{array}{l}\text { Jen-Chen Tsai et } \\
\text { al. }\end{array}$ & $\begin{array}{c}20-60 \text { years of } \\
\text { age }\end{array}$ & 102 & Yes & Yes \\
\hline $\begin{array}{l}\text { Josiane Lima de } \\
\text { Gusmao et al. }\end{array}$ & $54 \geq 8$ years & 77 & Yes & Yes \\
\hline $\begin{array}{l}\text { Didem } \\
\text { Arslantas, et al. }\end{array}$ & $\begin{array}{r}20 \text { years of } \\
\text { age }\end{array}$ & 1193 & Yes & Yes \\
\hline
\end{tabular}




\section{Chapter IV}

\section{METHODOLOGY}

This study is a pilot study for a childhood obesity prevention five year study using a CBPR approach with integration from Extension, research and education. Due to the purpose of the pilot study, which was to test the measurements, curriculum and feasibility of this study across five states, assessments at 0 (T0) and 4(T1) months for child/adult dyads (49=dyads) were collected. The dyad is made up of a child and an adult that is the child's main preparer of food in the home. The design is a one-group, pre-, post- assessment study across Maine, Nebraska, South Dakota, Tennessee and West Virginia. Research teams, including Extention Agents, Students and Researchers, in all five states were trained by webinars and then conducting IRR with $<0.5$ probability. West Virginia was responsible for BP training. In each state, dyad pairs were recruited to participate in a 12 week, 6-session educational program designed to improve culinary skills, family mealtime and physical activity to include play time interaction from the development of a web-site and by giving a video camera to document this interaction. Youth were also able to create and share, on a secure study website, short teaching videos they developed to demonstrate their involvement in cooking, mealtime and activity at home or in their own community.

The pilot study inclusion criteria is that the participant could not have a life threatening illness, and seemingly healthy. Sabine et al looked at pediatric and youth in a multi-faceted education program to determine if it had a positive impact on hypertension. The inclusion for this study was the participant had to have uncontrolled office blood pressure measurements. $(>160 / 95$ or $>140 / 90$ $\mathrm{mmHg}$ ) They did see a significant reduction in blood pressure but the fact that they had to have uncontrollable hypertension to begin with is like so many other studies. ${ }^{34}$ This sets iCook $4 \mathrm{H}$ out from many other studies because it is looking at otherwise healthy participants and trying to work 
on behavior change with SCT in education to impact BP, BMI, and QoL. Results also indicated that participants BMI did not change significantly and with growing children, this is positive.

The intervention contained 6 sessions every other week for a total of 12 weeks. Each session had a focus on a particular culinary skill, using a specific recipe and nutrient focus, and family engagement tasks such as setting the table or creating a menu and understanding physical activity and the importance of doing all these items together when possible. Table 2 represents the 6 sessions and there specific weekly focus. Fidelity was performed within multiple sessions to ensure timing was adequate and similar across the boards as well as assessments for the parent and child dyads given at the end of each session to help determine content.

Table 2. iCook4H Curriculm Session Overview for the Pilot Study

\begin{tabular}{|l|l|l|l|l|}
\hline Session & $\begin{array}{l}\text { Culinary } \\
\text { Skills }\end{array}$ & PA Skills & Nutrient Focus & $\begin{array}{l}\text { Family } \\
\text { Engagement }\end{array}$ \\
\hline $\mathbf{1}$ & $\begin{array}{l}\text { Cool Cooks } \\
\text { Tools }\end{array}$ & $\begin{array}{l}\text { Goal Setting } \\
\text { for eating and } \\
\text { PA }\end{array}$ & $\begin{array}{l}\text { Fruits and Vegetables: } \\
\text { More Matters }\end{array}$ & $\begin{array}{l}\text { Dinner Time Talk } \\
\text { Strategies }\end{array}$ \\
\hline $\mathbf{2}$ & $\begin{array}{l}\text { Food Safety } \\
\text { Basics }\end{array}$ & Stretching & $\begin{array}{l}\text { The Whole Story on } \\
\text { Whole Grains }\end{array}$ & $\begin{array}{l}\text { Division of } \\
\text { Responsibilities }\end{array}$ \\
\hline 3 & $\begin{array}{l}\text { The Art of Meal } \\
\text { Planning }\end{array}$ & $\begin{array}{l}\text { Healthy } \\
\text { Downtime }\end{array}$ & Nutritious Beverages & $\begin{array}{l}\text { Family-focused } \\
\text { mealtime with } \\
\text { controlled use of } \\
\text { "screen time" }\end{array}$ \\
\hline 4 & $\begin{array}{l}\text { Grocery } \\
\text { Shopping }\end{array}$ & $\begin{array}{l}\text { Know Your } \\
\text { Ileart Rate }\end{array}$ & Focus on Healthy Fats & $\begin{array}{l}\text { Improve family } \\
\text { communication } \\
\text { through daily food } \\
\text { proparation }\end{array}$ \\
\hline $\mathbf{5}$ & Eating Together & Active Play & Dairy Does It & $\begin{array}{l}\text { Identifying games } \\
\text { for the whole } \\
\text { family }\end{array}$ \\
\hline 6 & $\begin{array}{l}\text { Spices and } \\
\text { Seasoning }\end{array}$ & $\begin{array}{l}\text { Building } \\
\text { Strong } \\
\text { Muscles }\end{array}$ & Power Protein & $\begin{array}{l}\text { I love it, I like it, } \\
\text { No thank you, } \\
\text { Differences in taste }\end{array}$ \\
\hline
\end{tabular}

Recruitment involved selecting a convenience sample of family dyads of 9-10 year old youth and the primary adult meal preparer. In addition, to be eligible they need to be free from lifethreatening illness or other conditions and/or activity-related medical restrictions that would prevent participation in a face-to-face nutrition and fitness program, and have regular access to computer with Internet connection. Potential participants were reached by sending fliers home with children before school ended for the summer. Informational emails were sent out to 4-H club 
members as well as Home Schooled listings. Churches and 4-H camps were the last efforts for recruitment before the intervention began.

Participant incentives were a video camera for the child and $\$ 100$ total, distributed as $\$ 10$ gift cards for both child and adult at pre and post assessments $(\$ 40)$, and $\$ 60$ in gift cards for the adults, distributed in $\$ 10$ increments at each of the six educational sessions. Participants must have attended the sessions to receive incentives. The researcher received training in human subjects research and all methods were approved by the Human Subjects Institutional Review Board for each participating state. IRR was established on a representative sample of 8-11 year olds until a p-value $>0.8$ was established.

At each assessment period T0 and T1, the child completed two online surveys that included; Peds-QL, a 23-item questionnaire used to assess quality of life in the children. ${ }^{35}$ (See Appendix C) This survey is validated for use in children between the ages of 5 and 17 years. Other survey items included Eating Habits, a 10-item subscale from Project EAT to assess eating habits, Family mealtime where children describe their family meal times using a 10-item questionnaire, Cooking Skills Measurement, a 6-item instrument designed to elicit a child's comfort level with specific cooking skills, and the Block Food and Activity Screener for Ages 2-17 that helps measure foods eaten last week. The survey also requested demographic information including state, age, school grade, gender, and race. Surveys were administered through Qualtrics, a survey tool used for creating and conducting surveys and through the nutrition block website. ${ }^{36}$

Physical assessments were collected (see Appendix D) to include waist circumference which was measured with a gulick tape measure at the iliac crest to the nearest 0.1 centimeter. Height was measured with shoes off on a portable stadiometer to the nearest 0.1 centimeter. Weight was measured with a digital scale to the nearest 0.2 kilogram and physical activity was measured with a 
gt $3 \mathrm{x}$ accelerometer that was asked to be worn for seven days. Body mass index was calculated using height and weight.

The child's blood pressure was taken with the Omron HEM 907 XL Intellisense Prof. Digital BP monitor with an initial rest time of 5 minutes and 2 minutes of rest in between measurements. ${ }^{37}$ An average of 3 measurements was then recorded. Using the National Heart, Lung, and Blood Institutes "Pocket Guide to Blood Pressure Measurement in Children" the BP classification was then recorded (see Appendix D). Procedures for taking blood pressure are those outlined from the CARDIAC Project Surveillance Intervention Research. ${ }^{20}$

Data was analyzed using SAS $9.3^{38}$ and REDCap ${ }^{39}$. Frequencies were determined with demographics and measures (see Appendix C). Match paired t tests were done with SBP, DBP, BMI, and Peds-QL to determine if there were significant changes between pre and post assessment. The Pearson's correlation coefficient was used to determine if there were any correlations between BP and Peds-Q1, and BMI and BP. A positive correlation was defined as 0.3 equal or greater and a negative correlation at -0.3 equal or less. Statistical significance was assigned at $<0.05$ level of probability. 


\section{CHAPTER V RESULTS}

Youth participatants $(\mathrm{n}=49)$ enrolled in the program and provided demographic and physical assessment measures. Table 3 shows demographic data of children with the majority being 10 years old (56\%), female (65\%), and white (61\%).

\section{Table 3 Demographics}

\begin{tabular}{|l|l|}
\multicolumn{1}{|c|}{ Variable } & Percent \\
\hline \multicolumn{1}{|c|}{ Statc } \\
Maine
\end{tabular}

Table 4 displays Pearson's correlation which was used to determine if there was a linear correlation between the different variables. BMI and SBP were significantly correlated as well as BMI and DBP. 
Table 4 Pearson's Correlation

\begin{tabular}{|l|c|c|}
\hline $\begin{array}{l}\text { Correlated } \\
\text { Variables }\end{array}$ & $\begin{array}{c}\text { R } \\
\text { (Baseline) } \\
\text { p-value }\end{array}$ & R (Post) \\
\hline BMI vs. SBP & 0.65 & $0.65^{*}$ \\
& $<0.0001$ & $<0.001$ \\
\hline BMI vs. DBP & 0.57 & $0.43^{*}$ \\
\hline SBP vs. Peds- QoL & 0.06 & -0.03 \\
& 0.6934 & 0.8495 \\
\hline DBP vs. Peds-QoL & -0.05 & -0.03 \\
& 0.7335 & 0.8477 \\
\hline
\end{tabular}

Table 5 displays results from Matched Paired T Test and failed to reject the null in all but the PedsQL with an alpha=0.05, t-value of -3.07 and p-value 0.0042 .

\section{Table 5 Match Paired T Test}

\begin{tabular}{|l|c|c|}
\hline Difference & t Value & P-value \\
\hline $\begin{array}{l}\text { SBP (pre) vs. } \\
\text { (post) }\end{array}$ & 0.29 & 0.7737 \\
\hline $\begin{array}{l}\text { DBP (pre) vs. } \\
\text { (post) }\end{array}$ & -0.25 & 0.8959 \\
\hline $\begin{array}{l}\text { BMI (pre) vs. } \\
\text { (post) }\end{array}$ & -0.48 & 0.6322 \\
\hline $\begin{array}{l}\text { Peds-QoL } \\
\text { (pre)vs.(post) }\end{array}$ & -3.07 & $0.0042^{*}$ \\
\hline
\end{tabular}

Alpha $=0.05$ 


\section{CHAPTER VI DISCUSSION}

This study's findings support that the iCook4H 12 week 6 sessions intervention can have a positive impact on improving Peds-QL in youth ages 9-10. The results indicate that a program designed to educate youth in hopes of preventing obesity has a significant positive impact in physical, emotional, and social functioning. It is hypothesized that the classes offered a "group" feel and helped the youth feel more connected to others. This could be accounted to the social cognitive theory used in developing iCook $4 \mathrm{H}$ curriculum, the "learn by doing" method. It could also be attributed to the relationship with the parent participating in the class and empowering the child through this partnership

The results from this study coincide with the result that Angela Bernendes et al. found when looking at 7,688 youth ages 11-17. Bernendes et al. found no correlation between BP and QoL. The tool used to measure QoL was KINDL-R which is different than the Peds-QL tool used in iCook4 H but is comparable. They also found that those who were hypertensive had better quality of life scores in better well-being and low distress. This is the opposite of what one would think but they suggest this could be due to repressed emotions which resulted in elevated blood

pressure. Garcia et al was another study that did not have an intervention, but measured QUL and BP in Brazil. They found that high SBP and DBP were significantly higher in children with bad QUL. This study is different from iCook4H because it did not have an intervention; it was solely trying to determine if there is a correlation between BP and QoL in youth. ${ }^{27}$

Croker et al. was similar to iCook $4 \mathrm{H}$ in the fact that it did have an intervention between measurements and also used Peds-QL tool to measure QoL in their participants. Croker et al. looked at 72 overweight and obese youth ages 8-12 and found an improvement in BP as well as 
an improvement in QoL. ${ }^{29}$ The main difference in this intervention is that they intentionally recruited children classified overweight where as iCook4H did not narrow their recruitment to a specific classification. Studies looking at BP and QoL in youth are very limited and have resulted in conflicting data. Another study that used FBBT in their intervention saw a significant reduction in systolic BP and improvements in QoL but they recruited adolescents classified as overweight or obese as well. The FBBT asked that the child and guardian attend classes together similar to iCook $4 \mathrm{H} .{ }^{29}$ Since there is limited research on quality of life in apparently healthy individuals participating in an intervention more research is needed in this area.

Harvard's School of Public Health states that "as BMI increases, so do blood pressure, LDL, triglycerides, blood sugar, and inflammation." ${ }^{40}$ There was no correlation found between BP and QoL so a Pearson's correlation was run between BMI and BP to ensure data is consistent to previous findings. BP and BMI were found to positively correlate. This is similar to what McNeice et al found in their study looking at 6790 adolescents (11-17 years) in Houston schools. ${ }^{11}$ Pre-hypertension, stage 1 hypertension, and stage 2 hypertension all showed a statistically significant trend for increasing prevalence with increasing BMI percentile. ${ }^{11}$

Blood pressure measures from pre to post assessment had no significant change, however normal BP went from $92.5 \%$ to $90.1 \%$ yet Pre-Hypertension went from $5.7 \%$ to $9.1 \%$. The cause of this increase is unknown, but the number of measurements went from 53 to 55 which had some impact on this increase. . Unlike iCook4H's obesity prevention intervention, Kalarchian et al did an obesity treatment intervention where they found that BP decreased significantly after the intervention. The difference in results between this and iCook4H could be attributed to the target population for recruitment (obese vs. apparently healthy) respectively. Many studies done with youth and blood pressure are fairly new in the health population. This is because youth weren't 
previously at such an increased risk of developing hypertension. Due to the rise in obesity, hypertension is increasing as a secondary disease and needs to be monitored for adequate treatment and prevention. McNeice et al. found that approximately $20 \%$ of adolescents are at risk for hypertension which stresses the importance of more research in this particular field. ${ }^{11}$

\section{Limitations}

This was a pilot study with no control group using a convenience sample of the target population. The purpose it served was large for the understanding of the measures, curriculum effectiveness, feasibility and fidelity. The small participant sample size was small across all state partners therefore its intention was not to measure significants and the researchers realized statistical power was lacking in this pilot study. 


\section{Chapter VII CONCLUSION}

Due to the increasing rise in adolescent and pediatric obesity, there is an increase in multiple health complications. Pediatric hypertension is one of the possible complications that can have detrimental effects. Hypertension in children and adolescents persist into adulthood and is a significant risk factor for CVD which is the number one killer in the United States. With the pilot iCook4H study there was no significant change in BP or BMI from pre to post assessment. There was also not a correlation found between BP and Peds-QL however there was a positive correlation found between $\mathrm{BMI}$ and $\mathrm{BP}$ which is consistent to previous findings in the literature. Lastly, there was a significant improvement in Peds-QL from pre to post assessment. 


\section{Bibliography}

1. CDC/National Center for Health Statistics. Leading causes of death. Center for Disease Control and Prevention Web site. http://www.cdc.gov/nchs/fastats/lcod.htm. Updated October 19, 2012. Accessed 10/31, 2012.

2. CDC grand rounds: Childhood obesity in the united states. MMWR Morb Mortal Wkly Rep. 2011;60(2):42-46. http://search.ebscohost.com/login.aspx?direct=true $\& d b=c 8 h \& A N=2010918986 \&$ site $=$ ehost-live.

3. Obesity evaluation and treatment: Expert committee recommendations. Pediatrics. 1998;102(3):626.

http://search.ebscohost.com/login.aspx?direct=true\&db=hch\&AN=1073200\&site=ehost-live.

4. The fourth report on the diagnosis, evaluation, and treatment of high blood pressure in children and adolescents. Pediatrics. 2004;114:555-576.

http://search.ebscohost.com/login.aspx?direct=true $\& \mathrm{db}=\mathrm{hxh} \& \mathrm{AN}=13855584 \&$ site=ehost-live.

5. Sorof J, Daniels S. Obesity hypertension in children: A problem of epidemic proportions. Hypertension. 2002;40(4):441-447.

6. Cromwell PF, Munn N, Zolkowski-Wynne J. Evaluation and management of hypertension in children and adolescents (part one): Diagnosis. Journal of Pediatric Health Care. 2005;19(3):172175. doi: 10.1016/j.pedhc.2005.02.005.

7. Garcia FD, Terra AF, Queiroz AM, et al. [Evaluation of risk factors associated with increased blood pressure in children]. J Pediatr (Rio J). 2004;80(1):29-34.

http://search.ebscohost.com/login.aspx?direct=true \&db=cmedm\&AN=14978546\&site=ehost-live.

8. Mahoney LT, Clarke WR, Burns TL, Lauer RM. Childhood predictors of high blood pressure. Am J Hypertens. 1991;4(11):608S-610S.

9. Kavey RE, Daniels SR, Flynn JT. Management of high blood pressure in children and adolescents. Cardiol Clin. 2010;28(4):597-607.

http://search.ebscohost.com/login.aspx?direct=true \&db=c8h\&AN=2010827265\&site=ehost-live. doi: 10.1016/j.ccl.2010.07.004.

10. Chen X, Wang Y, Appel LJ, Mi J. Impacts of measurement protocols on blood pressure tracking from childhood into adulthood: A metaregression analysis. Hypertension. 2008;51(3):642649. doi: 10.1161/HYPERTENSIONAHA.107.102145;

10.1161/HYPERTENSIONAHA.107.102145.

11. McNiece KL, Poffenbarger TS, Turner JL, Franco KD, Sorof JM, Portman RJ. Prevalence of hypertension and pre-hypertension among adolescents. J Pediatr. 2007;150(6):640-4, 644.e1. doi: 10.1016/j.jpeds.2007.01.052. 
12. Kobayashi K, Kamibeppu K. Quality of life reporting by parent-child dyads in japan, as grouped by depressive status. Nurs Health Sci. 2011;13(2):170-177.

http://search.ebscohost.com/login.aspx?direct=true\&db=c8h\&AN=2011065355\&site=ehost-live. doi: 10.1111/j.1442-2018.2011.00595.x.

13. Keating CL, Moodie ML, Swinburn BA. The health-related quality of life of overweight and obese adolescents - a study measuring body mass index and adolescent-reported perceptions. International Journal of Pediatric Obesity. 2011;6(5):434-441. http://search.ebscohost.com/login.aspx?direct=true\&db=lbh\&AN=20113321749\&site=ehost-live; http://informahealthcare.com/doi/abs/10.3109/17477166.2011.590197.

14. Ingerski LM, Janicke DM, Silverstein JH. Brief report: Quality of life in overweight youth-the role of multiple informants and perceived social support. J Pediatr Psychol. 2007;32(7):869-874. http://search.ebscohost.com/login.aspx $?$ direct=true $\& \mathrm{db}=\mathrm{cmedm} \& \mathrm{AN}=17488775 \&$ site=ehost-live.

15. Morrow AM, Quine S, Heaton MD, Craig JC. Assessing quality of life in paediatric clinical practice. J Paediatr Child Health. 2010;46(6):323-328.

http://search.ebscohost.com/login.aspx ?direct=true \&db=psyh\&AN=2010-13106-010\&site=ehostlive. doi: 10.1111/j.1440-1754.2010.01716.x.

16. Wallerstein N, Duran B. Community-based participatory research contributions to intervention research: The intersection of science and practice to improve health equity. Am J Public Health. 2010;100(S1):S40-S46.

17. Lazarus S, Duran B, Caldwell L, Bulbulia S. Public health research and action: Reflections on challenges and possibilities of community-based participatory research. Public Health.Intech (Open Access Publisher: www.intechweb.org). 2012.

18. Israel BA, Coombe CM, Cheezum RR, et al. Community-based participatory research: A capacity-building approach for policy advocacy aimed at eliminating health disparities. Journal Information. 2010;100(11).

19. Becker AB, Israel BA, Allen A. Strategies and techniques for effective group process in CBPR partnerships. Methods in community-based participatory research for health. 2005:52-72.

20. Demerath E, Muratova V, Spangler E, Li J, Minor VE, Neal WA. School-based obesity screening in rural appalachia. Prev Med. 2003;37(6):553-560. doi: 10.1016/j.ypmed.2003.09.013.

21. Colin-Ramirez E, Castillo-Martinez L, Orea-Tejeda A, Villa Romero AR, Vergara Castaneda A, Asensio Lafuente E. Waist circumference and fat intake are associated with high blood pressure in mexican children aged 8 to 10 years. J Am Diet Assoc. 2009;109(6):996-1003. doi:

10.1016/j.jada.2009.03.011; 10.1016/j.jada.2009.03.011. 
22. Raman A, Sharma S, Fitch MD, Fleming SE. Anthropometric correlates of lipoprotein profile and blood pressure in high BMI african american children. Acta Paediatr. 2010;99(6):912-919. doi: 10.1111/j.1651-2227.2009.01639.x; 10.1111/j.1651-2227.2009.01639.x.

23. Gittner LS, Hassanein SE, Murphy PJ. Church-based heart health project: Health status of urban african americans. Perm J. 2007;11(3):21-25. http://search.ebscohost.com/login.aspx?direct=true $\& d b=c m e d m \& A N=21461108 \&$ site=ehost-live.

24. Claire Friedemann, Carl Heneghan, Kamal Mahtani, Matthew Thompson, Rafael Perera, Alison M Ward. Cardiovascular disease risk in healthy children and its association with body mass index: Systematic review and meta-analysis. BMJ. 2012;345. doi: 10.1136/bmj.e4759.

25. Kalarchian MA, Levine MD, Arslanian SA, et al. Family-based treatment of severe pediatric obesity: Randomized, controlled trial. Pediatrics. 2009;124(4):1060-1068. http://search.ebscohost.com/login.aspx?direct=true \&db=c8h\&AN=2010434928\&site=ehost-live. doi: $\underline{\text { http://dx.doi.org/10.1542/peds.2008-3727. }}$

26. Schuster MA, Elliott MN, Kanouse DE, et al. Racial and ethnic health disparities among fifthgraders in three cities. $N$ Engl J Med. 2012;367(8):735-745.

http://search.ebscohost.com/login.aspx?direct=true\&db=lbh\&AN=20123277573\&site=ehost-live; http://www.nejm.org/medical-index.

27. Berendes A, Meyer T, Hulpke-Wette M, Herrmann-Lingen C. Association of elevated blood pressure with low distress and good quality of life: Results from the nationwide representative german health interview and examination survey for children and adolescents. Psychosom Med. 2013;75(4):422-428.

http://search.ebscohost.com/login.aspx?direct=true \&db=cmedm\&AN=23645707\&site=ehost-live. doi: 10.1097/PSY.0b013e31828ef0c2.

28. Foster GD, Sundal D, McDermott C, Jelalian E, Lent MR, Vojta D. Feasibility and preliminary outcomes of a scalable, community-based treatment of childhood obesity. Pediatrics.

2012;130(4):652-659. doi: 10.1542/peds.2012-0344.

29. Croker H, Viner RM, Nicholls D, et al. Family-based behavioural treatment of childhood obesity in a UK national health service setting: Randomized controlled trial. Int J Obes (Lond). 2012;36(1):16-26.

http://search.ebscohost.com/login.aspx?direct=true\&db=cmedm\&AN=21931327\&site=ehost-live. doi: 10.1038/ijo.2011.182.

30. Ogden CL, Troiano RP, Briefel RR, Kuczmarski RJ, Flegal KM, Johnson CL. Prevalence of overweight among preschool children in the united states, 1971 through 1994. Pediatrics. 1997;99(4):e1-e1. doi: 10.1542/peds.99.4.e1.

31. Tsai J, Yang H, Wang W, et al. The beneficial effect of regular endurance exercise training on blood pressure and quality of life in patients with hypertension. Clin Exp Hypertens. 
2004;26(3):255-265.

http://search.ebscohost.com/login.aspx?direct=true \&db=cmedm\&AN=15132303\&site=ehost-live.

32. Spruill TM, Feltheimer SD, Harlapur M, et al. Are there consequences of labeling patients with prehypertension? an experimental study of effects on blood pressure and quality of life. $J$ Psychosom Res. 2013;74(5):433-438.

http://search.ebscohost.com/login.aspx ?direct=true $\& \mathrm{db}=\mathrm{cmedm} \& \mathrm{AN}=23597332 \&$ site=ehost-live. doi: 10.1016/j.jpsychores.2013.01.009.

33. Zygmuntowicz M, Owczarek A, Elibol A, Olszanecka-Glinianowicz M, Chudek J. Blood pressure for optimal health-related quality of life in hypertensive patients. J Hypertens. 2013;31(4):830-839. http://search.ebscohost.com/login. aspx ?direct=true $\& d b=c 8 h \& A N=2012035532 \&$ site=ehost-live. doi: 10.1097/HJH.0b013e32835ebdd7.

34. Perl S, Riegelnik V, Mrak P, et al. Effects of a multifaceted educational program on blood pressure and cardiovascular risk in hypertensive patients: The austrian herz.leben project. $J$ Hypertens. 2011;29(10):2024-2030. doi: 10.1097/HJH.0b013e32834aa769

35. Peds-QL self-reported children 8-12, Licensor: Dr. James W. Varni http://www.pedsql.org/

36. The [output/code/data analysis] for this paper was generated using Qualtrics software, Qualtrics Research Suite. Copyright ( 9 [2014] Qualtrics. Qualtrics and all other Qualtrics product or service names are registered trademarks or trademarks of Qualtrics, Provo, UT, USA. http://www.qualtrics.com

37. Blood Pressure (Mg.), Model HEM-907XL, Omron Digital Model Lake Forest, IL

38. The [output/code/data analysis] for this paper was generated using SAS software, Version 9.3 of the SAS System for [Unix]. Copyright 2014 SAS Institute Inc. SAS and all other SAS Institute Inc. product or service names are registered trademarks or trademarks of SAS Institute Inc., Cary, NC, USA.

39. Paul A. Harris, Robert Taylor, Robert Thielke, Jonathon Payne, Nathaniel Gonzalez, Jose G. Conde, Research electronic data capture (REDCap) - A metadata-driven methodology and workflow process for providing translational research informatics support, J Biomed Inform. 2009 Apr;42(2):377-81.

40. Harvard School of Public Health. Obesity Prevention. 2014. Accessed 3/8/14. http://www.hsph.harvard.edu/obesity-prevention-source/obesity-consequences/health-effects/

41. Longitudinal physical activity and sedentary behavior trends: Adolescence to adulthood Gordon-Larsen P., Nelson M.C., Popkin B.M. (2004) American Journal of Preventive Medicine, 27 (4) , pp. 277-283. 
42. Overweight in children. 2014. Accessed 3/8/14.

https://www.heart.org/HEARTORG/GettingHealthy/HealthierKids/ChildhoodObesity/Overweig ht-in-Children_UCM_304054_Article.jsp

43. America's move to raise a healthier generation. 2014. Accessed 3/8/14 http://www.letsmove.gov/

44. Eto K, Koch P, Contento IR, Adachi M. Variables of the theory of planned behavior are associated with family meal frequency among adolescents. J Nutr Educ Behav. 2011;43(6):525530. doi: 10.1016/j.jneb.2011.05.010.

45. Short, F. Domestic cooking skills-what are they? Journal of the Home Economics Institute of Australia, 2003; 10(3), 13-22.

46. USDA. (2007). Food CPI, Prices, and Expenditures. Economic. Economic Research Service. United States Department of Agriculture. Accessed November 14, 2008, from:http://www.ers.usda.gov/

47. Office of Behavioral and Social Sciences Research. Social and behavioral theories. Accessed April 3, 2014, from:

http://www.esourceresearch.org/eSourceBook/SocialandBehavioralTheories/5InterventionstoCha ngeHealthBehavior/tabid/737/Default.aspx

48. Boston University School of Public Health. Date last modified: January 22, 2013. Accessed 4/3/14. http://sphweb.bumc.bu.edu/otlt/MPH-Modules/SB/SB721-Models/SB721-Models5.html 


\section{APPENDICIES \\ Appendix A \\ Institutional Review Board Approval and Consent/Assent and Information Form}

WVU IRB Approved Protocol H-24315 Title: iCook Childhood Obesity Prevention Study using Culinary Skills and Family Conversation Time in 9-10 year olds

The 45 page document including consent/assent can be found in the BRAAN 2 system with the tracking number $\mathrm{H}-24315$. 


\section{Appendix B \\ Peds Quality of Life Inventory Survey}




\section{Appendix C \\ Youth Demographics}

- When is your birthday?

- What grade are you in school?

- Are you a boy or a girl?

- What is your race?

o White

o Black

o Asian

o Hispanic

o Native American

o Other 


\section{Appendix D \\ Anthropometric, Blood Pressure and Body Composition Measures}

\section{General Study Procedures}

- All scales must be calibrated prior to use and calibrated periodically during measurement.

- Each anthropometric measurement must be taken at least twice and recorded immediately (consider having a recorder available to facilitate this process and reduce errors).

- Each measurement must be entered into the online database. It is recommended that this be done either during or at the end of each day of measurement.

- An independent observer must verify that the data recorded on the NRI data recording sheet (Appendix) and the data recorded in the Excel database are the same. This observer should initial both copies, verifying that the data are correct. Corrections need to be noted under comments.

- Be mindful of the units of measurement used. For example, if the balance beam scale has both metric and English measures, assessors must be clear about which notch on the beam goes with which type of measure-metric should be used.

- All height and weight data must be reported in metric units: centimeters and kilograms, respectively. Waist circumference will be recorded in centimeters.

\section{Weight Assessment}

Body weight is the most common anthropometric measurement used, and has the advantages that it is safe, non-invasive, and inexpensive. Weight measurement is easy to train to unskilled people, and weight reflects past changes and assesses growth and can be used to identify malnutrition. Weight should be the $1^{\text {st }}$ assessment conducted during the assessment appointment.

\section{Required Item(s) for Weight Assessment}

- Digital scale

- Standardized weights for calibration

- Stool or chair to allow participant to remove shoes and socks

- Extra t-shirts and shorts available, if needed

- Nearby restroom facilities

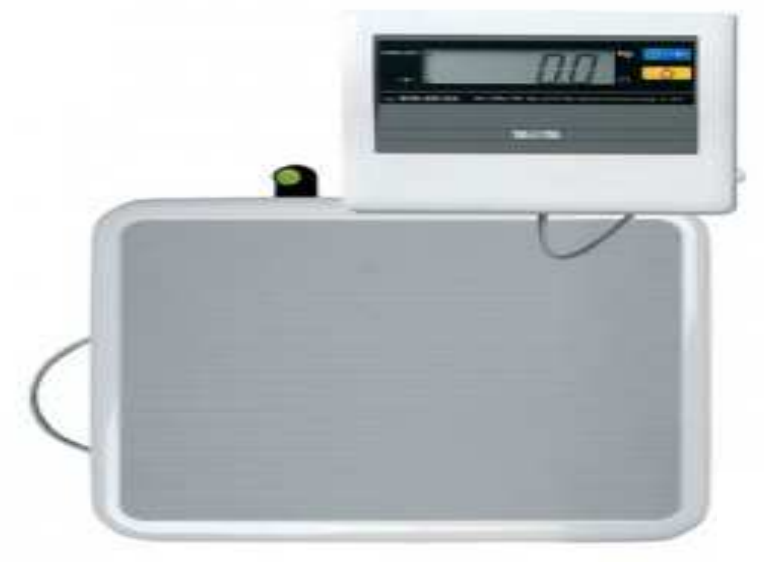

Figure 1. Digital Scale 


\section{Important Notes}

- Due to natural weight fluctuations that occur during the day, it is desirable to weigh the participant at the same time of day (within 2 hours) for each assessment.

- To measure weight accurately, scales should be recalibrated on a regular basis and each time a scale is moved to a different location. Please review your scale manual for proper calibration techniques or contact an appropriate representative.

- The current recommendations for taking weight are to have the participant facing away from the balance beam or digital readout to reduce panicking and moving their hands and body.

- Educate your staff about the importance of not commenting on the participant's weight and not responding if the participant does comment. Staff can say, for example, "thank you for helping us with this measurement."

- Please ensure the same scale is used for all weight measurements.

\section{Weight Assessment Protocol}

1. Zero the scale. Balance beam scales must be level prior to weighing the participant. The scale must be on a hard, flat surface, not on carpet.

2. Ask participants to empty their bladder prior to being weighed. This is required of all participants.

3. Ask participants to remove excess clothing, shoes, and socks prior to being weighed.

4. Ask the participant step up onto scale fully. Staff must make sure that both feet are completely on the scale.

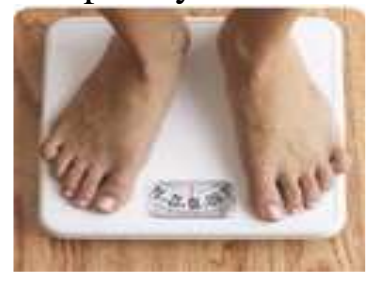

Figure 2. Feet placement on scale.

5. Ask the participant stand completely still with arms at sides and eyes looking straight ahead.

6. Record weight to the nearest $0.1 \mathrm{~kg}$ on the data collection sheet.

7. Repeat measurement. If there is $>0.2 \mathrm{~kg}$ difference between measurements, repeat until two measurements are within $0.2 \mathrm{~kg}$. These two agreeing measurements will be the official measurements.

8. Record all measurements on NRI data collection sheet. Be sure to cross out any unofficial measurements (i.e. those discarded due to excess disagreement).

9. Record the average of the two official measurements to two decimal places (e.g., $0.2+$ $0.3=0.5 / 2=0.25)$.

\section{Height Assessment}

The measurement of height is also one of the most fundamental and easily obtained measurements. It is measured using a wall-mounted stadiometer, assuming the person is able to stand unassisted. Height should be the $2^{\text {nd }}$ assessment conducted during the assessment appointment.

\section{Required Item(s) for Height Assessment}

- SECA 213 Portable Stadiometer 
- Step stool or chair

\section{Important Notes}

- Be sure that the stadiometer is located in a non-carpeted area.

- For obese participants, it can sometimes be difficult to have four points of contact with the vertical backboard or wall (see Step 4 below). In this case, it is important to have as many contact points as possible (at least two), making sure the subject is looking straight ahead.

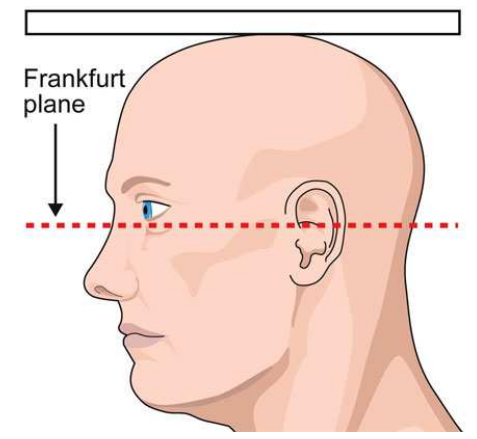

Figure 3: Frankfurt Plane

\section{Height Assessment Protocol}

1. Ask the participant to remove shoes.

2. Ask the participant to remove hair ornaments, buns, or barrettes that prevent the participant from placing his/her head against the back of the stadiometer.

3. Ask the participant to step completely under the slide of the stadiometer, making sure that the subject is centered with the stadiometer.

4. Ask the participant to stand as straight as possible with feet together and heels, buttock, shoulder blades, and back of head completely touching the wall (or as much as possible). This four-point contact will ensure that body weight is evenly distributed.

Figure 4:

Stadiometer setup

5. Be sure that the subject is looking straight ahead and that there is a horizontal plane from the bony socket of the eye to the notch above the projection of the ear.

6. Make sure the black stopper at the top of the stadiometer is pressed against the wall.

7. Ask the participant to take a deep breath in and hold it to straighten the spine and standardize measurement.

8. When the subject inhales, move the height slide to rest lightly on top of the participant's head.

9. Fix the height slide in place and ask the participant to resume normal breathing.

10. Record height to the nearest 0.1 centimeter on the data collection sheet. Be sure to avoid parallax (angular distortion) by bending down, kneeling or standing on a stool and reading the height value at eye level. 
11. Repeat measurement. If there is $>0.2$ centimeter difference between measurements, repeat until two measurements are within 0.2 centimeter. These two agreeing measurements will be the official measurements.

12. Record all measurements on the data collection sheet. Be sure to cross out any unofficial measurements (i.e. those discarded due to excess disagreement).

13. Record the average of the two official measurements to two decimal places (e.g., $0.2+$ $0.3=0.5 / 2=0.25)$.

\section{Waist Circumference Assessment}

A person's waist circumference is the most practical indicator of fat distribution and abdominal fat. It is often used in combination with BMI in the assessment of obesity. Waist Circumference should be the $3^{\text {rd }}$ assessment to be conducted during the assessment appointment.

\section{Required Item(s) for Waist Circumference Assessment}

- Gulick tape measure

- Washable marker

\section{Important Notes}

- Measurement of waist circumference may be uncomfortable to some individuals because they are exposing their bellies. Be sure measurements are conducted in a relatively private or screened-off area.

- Two people should work together to take this measurement, if possible, to ensure the tape is in a level horizontal plane and not twisted. A mirror or two corner mirrors are useful in making sure the tape is level.

- If an individual has a large abdominal fat mass, this measurement can be difficult. You must palpate the hip area until you feel the iliac crest.

\section{Waist Circumference Assessment Protocol}

1. Ask the participant to adjust his/her shorts or pants to a level just below the top of the hip bones and to raise his/her shirt to just above the umbilicus (belly button).

2. Locate and mark both iliac crests with a non-permanent marker. The iliac crests are the tops of the hip bones (see Figure 6).

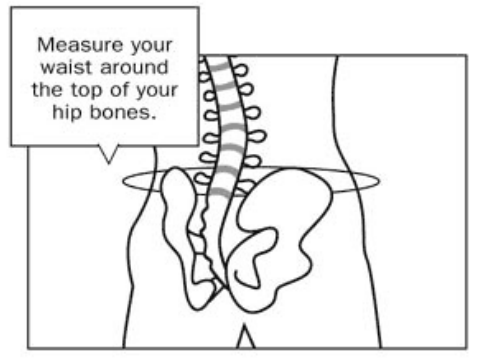

Figure 6. Waist circumference at the iliac crest.

3. Place the tape measure around the waist of the participant at the level of the marked iliac crests making sure that the tape is in a horizontal plane and not twisted.

4. Ask the participant to exhale to ensure that they are not holding in their belly. 
5. Upon the exhale, gently tighten the tape without compressing the skin.

6. Record the measurement to the nearest $0.1 \mathrm{~cm}$ on the data collection sheet.

7. Repeat measurement. If there is $>0.5 \mathrm{~cm}$ difference between measurements, repeat until two measurements are within $0.5 \mathrm{~cm}$. These two agreeing measurements will be the official measurements.

8. Record all measurements on the data collection sheet. Be sure to cross out any unofficial measurements (i.e. those discarded due to excess disagreement).

9. Record the average of the two official measurements to one decimal place (e.g., $2+3=$ $5 / 2=2.5)$.

\section{Tanner Staging Assessment}

Tanner staging maturation level will be completed in a private setting. A line drawing of male anatomy is shown to males and a line drawing of female anatomy will be shown to females. The child points at the appropriate stage of maturation and the iCook- $4 \mathrm{H}$ study team will document the response on a data collection form. Male researchers will ask male children and female researchers will ask female children. If this is not possible, an older female researcher will ask the question. This survey is required to appropriately classify the child when reporting maturation level and for determining correlations with the child's physical measurement and blood pressure.

\section{Blood Pressure Assessment}

Blood pressure should be the $4^{\text {th }}$ assessment to be conducted during the assessment appointment.

Important Information

This procedure needs to take place in a relatively quiet location. The participant should be as still as possible during the readings.

\section{Required Item(s) for Blood Pressure Assessment}

1.2 Omron HEM 907 XL Intellisense Prof. Digital BP monitor

\section{Blood Pressure Assessment Protocol}

1. Child should be sitting with arm resting on the table at heart level.

2. Avoid placing the cuff over clothing or a rolled up sleeve that might constrict the arm.

3. Make sure the cuff is the appropriated size

a. Cuff width should be $1 / 2$ to $2 / 3$ the upper arm length.

4. Palpate for the brachial artery pulse point

a.Found in the antecubital space on the little finger side of the palme-up extended arm.

b.Gently hyperextending the arm might make this easier to find.

5. Center the bladder over the brachial artery with the lowest egdge $2.5 \mathrm{~cm}$ above the antecubital space.

6. Obtain palpated systolic pressure and at $30 \mathrm{mmHg}$

7. Deflate rapidly and wait 30 seconds before reinflating

8. Apply bell head making a light but airtight seal over the palpable artery. The diaphragm end may be adequate, but the bell is preferable and may help block ambient noise.

9. Inflate rapidly to level determined in step 6.

10. Release pressure $2-3 \mathrm{mmHg} / \mathrm{sec}$. (slowly). 
11. Listen for onset of 2 consecutive beats, Korotkoff Phase 1, = systolic pressure.

12. Listen for the absence of sound, Korotkoff Phase 5, = diastolic pressure.

13. Deflate cuff and remove. Record reading.

\section{Body Mass Index (BMI)}

BMI is an index used as a screening tool to help determine an individual's risk for health problems related to too little or too much body fat. It is a mathematical calculation of the ratio between height and weight and is not a direct measure of body fat. The index is the same for men and women. Note that baseline BMI $<18.5$ is an exclusionary criterion for this study.

Table

\begin{tabular}{cl}
\hline BMI & Risk for Health Problems \\
\hline $\mathbf{1 8 . 5}$ & Increased risk \\
$\mathbf{1 8 . 5}-\mathbf{2 4 . 9}$ & Lowest risk \\
$\mathbf{2 5 . 0}-\mathbf{2 9 . 9}$ & $\begin{array}{l}\text { Low risk unless waist circumference is } \\
\text { high which slightly elevates risk }\end{array}$ \\
$\mathbf{3 0 ~ - 3 9 . 9}$ & Increased risk \\
$\mathbf{> 4 0 . 0}$ & Higher risk \\
\hline
\end{tabular}

If $\mathrm{BMI}$ is below 18.5 or above 30 , one may be at increased risk for health related problems. BMI below 18.5 can be indicative of malnutrition due to low calorie and protein intake, which results in low body muscle and fat (please note that persons with BMI $<18.5$ are not eligible to participate in the study). BMI above 30 may increase risk for developing conditions such as diabetes and high cholesterol. A high BMI is not necessarily indicative of risk for individuals with a lot of muscle mass, such as athletes because BMI will reflect muscularity rather than fatness for these individuals.

\section{Waist Circumference}

BMI is just one indicator of potential health risks associated with being overweight or obese. The National Heart, Lung, and Blood Institute guidelines also recommend measuring waist circumference because abdominal fat is an independent predictor of risk for obesity-related diseases.

Waist circumference is a common measure used to assess fat around one's waist (abdomen). The presence of excess body fat within the abdomen is considered a risk factor for health problems like diabetes. There are different waist circumference risk cut-points for men and women (see table below). Dietary patterns including whole grains, fruits, and vegetables and physically activity are recommended to minimize health risk. 


\begin{tabular}{cc}
\hline Sex & Waist Circumference \\
\hline Male & $>102 \mathrm{~cm}(40$ meteres $)$ \\
Female & $>88 \mathrm{~cm}(35$ meteres $)$ \\
\hline
\end{tabular}

\section{Interobserver Error Procedure}

\section{Purpose}

- To assess the degree of variation due to measurement error

\section{Requirements}

- At least 5 subjects to be measured

O One expert

- One or more observers

- Data record sheets (example in Appendix)

○ Excel file "Height", "Weight", and "Waist"

\section{Procedure}

1. The expert and all the observers measure height, weight, and waist circumference of all the subjects twice.

2. Record the data immediately on data collection sheet

3. Enter the data into the Excel worksheet "Measurement" (it will automatically calculate the Pearson's correlations between expert and observers, and the error in the worksheet "Evaluation" in the same Excel file).

Statistical note (Lohman, 1981):

$$
\begin{aligned}
& \mathrm{xi}=\text { measures by expert (average of three measurements) } \\
& \mathrm{yi}=\text { measures by observer } 1 \text { (average of three measurements) } \\
& \mathrm{X}=\text { mean of } \mathrm{xi} \\
& \mathrm{Y}=\text { mean of } \mathrm{yi} \\
& \mathrm{Sx}=\text { Standard deviation of expert } \\
& \mathrm{Sy}=\text { Standard deviation of observer } 1
\end{aligned}
$$

$$
\text { Peason's } r=\frac{\sum(x i-x)(y i-y)}{(n-1)(S x)(S y)}
$$

$$
\text { Spooled }=\frac{\sqrt{\left[(S x)^{2}+(S y)^{2}\right]}}{\sqrt{2}}
$$

Inter observer error $=\frac{S_{\text {pooled }} \sqrt{\left(1-\mathrm{r}^{2}\right)}}{\sqrt{2}}$ 


\section{Evaluation}

Pearson's $r$ ranges from -1 to +1 . The closer the Pearson's $r$ to 1 , the higher the correlation of the observer's measurement with the expert's.

Inter-observer error tells how an observer's measurements differ from an expert's. The unit of inter-observer error is the same as the measurement (inch for height, pound for weight, and centimeter for waist circumference).

\section{Physical Assessment Procedure}

\section{Review Sample Hard Copy of Informed Consent and Assent Forms}

2. Before you conduct the physical assessment, review a hard copy of the state-specific informed consent with adult and child and have adult sign the informed consent form. Prior to conducting the assessments, confirm the form you are to use with your PI.

a. If adult does not agree to sign the form, thank them for their time, let them know they are ineligible for the study, and follow your state protocol for providing the incentive.

b. If planning to take pictures of participants, have them sign the standard university photo release form.

c. Build rapport with the participant during this assessment period.

d. Keep the signed copy for state records

\section{Complete iCook-4H Project Data Collection Form}

a. Check to see that participants have appropriate clothing for the physical assessment. If not, please ask them to change into the clean, light clothing that you have available (i.e. t-shirt and gym shorts).

b. Fill in the contact information on the top part of the Data Collection Form.

c. Conduct the physical assessments. You will need to do two measurements of height, weight, waist circumference, and blood pressure and then average the two measurements. See details in the Physical Assessment Manual.

d. Provide Primary Care Prover Referral (Appendix E) to the following participants.

Baseline Assessment:

- Participants at who have low body mass indices (i.e. BMI < 18.5). Student is considered ineligible for the study.

3 Month Assessment, 12 Month, or 24 Month Assessment:

- Participants who have low body mass indices

- Participants who have risky behaviors

- Participants who have had at least $10 \%$ weight change between assessments

e. Provide student with incentive using state protocols. Make sure you have them sign that they received it on the Data Collection Form. Each campus coordinator may want to keep a spreadsheet of names, ID numbers and record of compensation for all participants.

f. Enter data and contact information (address and phone number) from the Data Collection Form into the iCook-4H website immediately after each physical assessment.

\section{Enter Physical Assessment Data}

a. Log-on to the website (www.icook4h.com) with your user name and password.

b. Click on People

c. Select Participant 
d. Enter information in appropriate text box.

\section{Securely Store Data Collection Forms}

a. After the physical assessment and/or entering physical assessment data, file the Data Collection Form in a secure location such as in a locked file cabinet.

b. Once you have completed all baseline, post intervention, and 15 month assessments, send a photocopy of page 2 of each participant's Data Collection Form and mail to Douglas Mathews at Department of Food Science and Human Nutrition 5735 Hitchner Hall Orono, ME 04469.

\section{Verify Participant Data}

The campus coordinator must designate a person (other than the one who entered the data) to verify the accuracy of each participant's data.Verification is done by checking the data against the Data Collection Form. 


\section{Appendix E}

\section{A Pocket Guide to BP Measurement in Children}

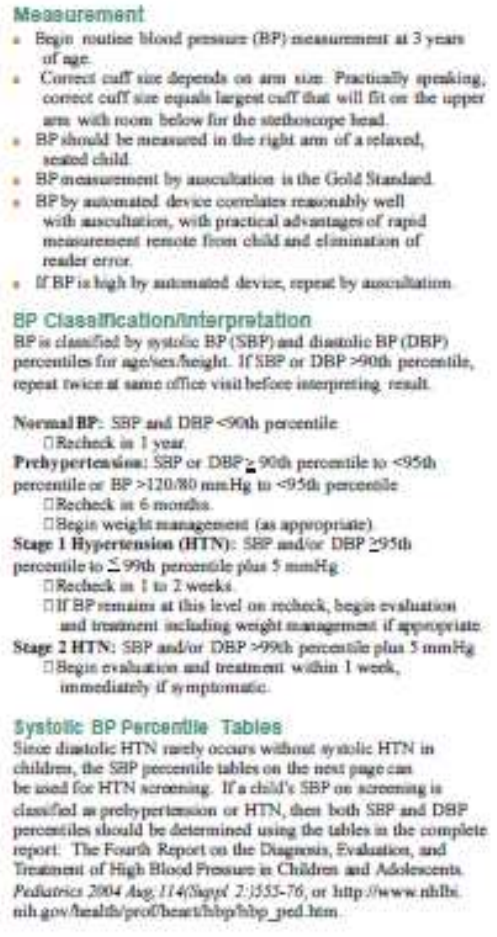

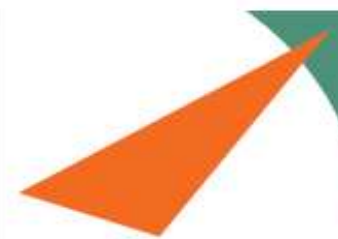

A Pocket Guide to Blood Pressure Measurement in Children

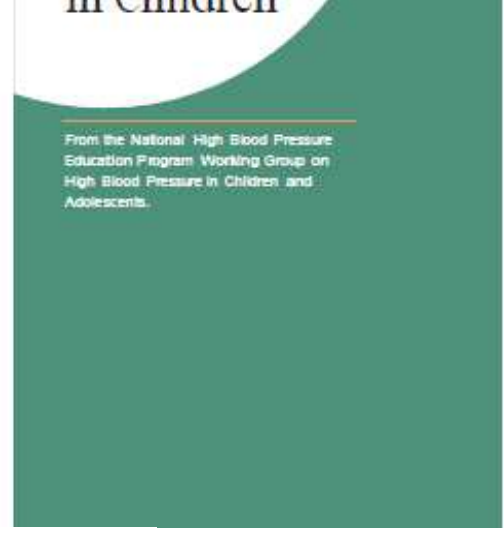

Oirectione for Use of Tables

1. Heighte in the table ane given firr age at midyeat. Une eluvesi liaght to interpure BP

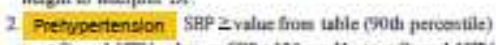

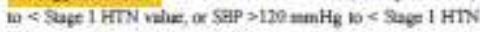
value

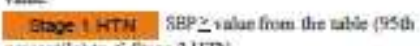
gacentile) b $\mathrm{S}$ Stace $2 \mathrm{HTN}$ pacentile) b 1 Staje 2. HTN. Fius $5 \mathrm{minHz}$

For atiofe idformation go to www shithinith gen
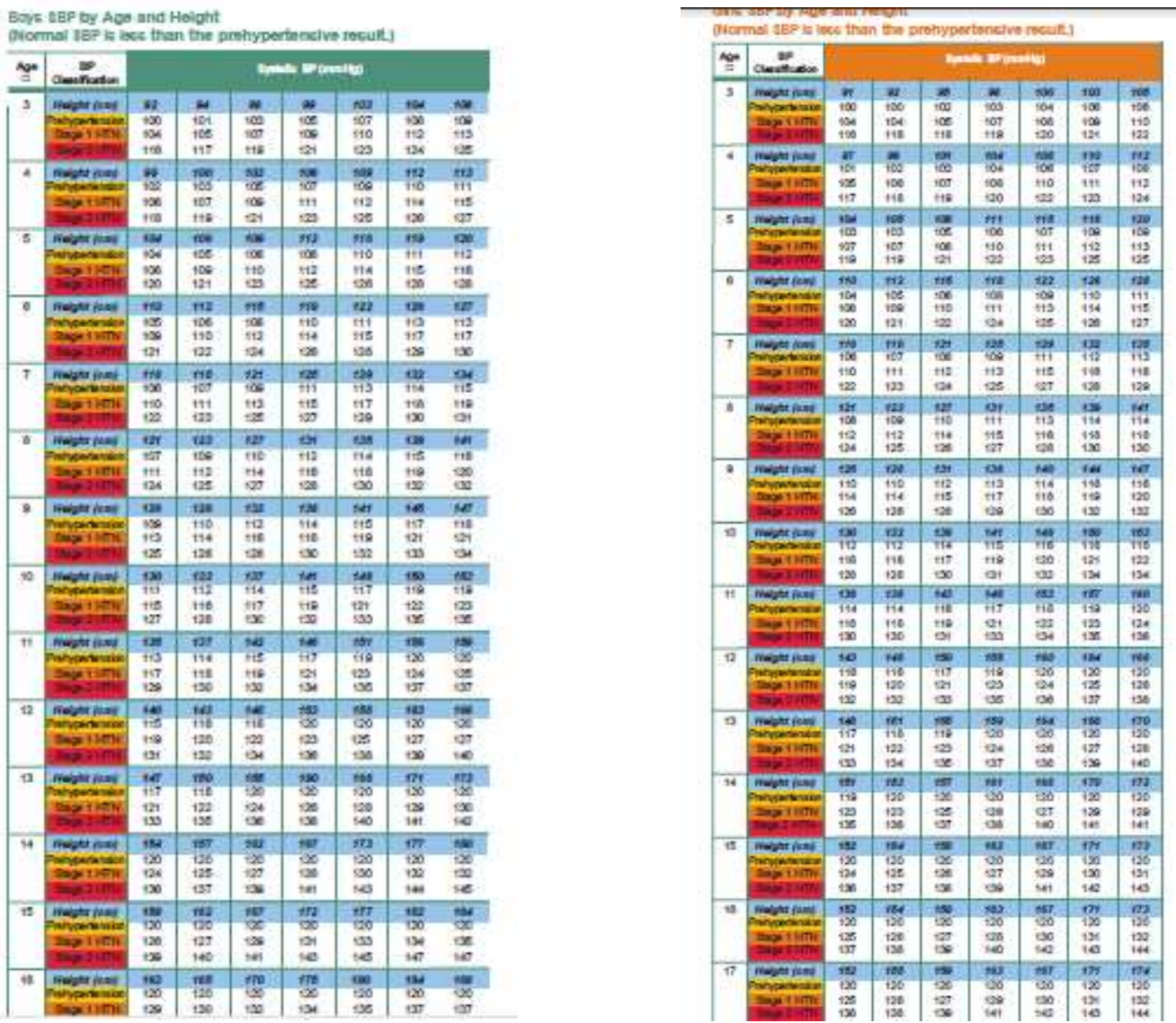